\title{
Predicting the effect of constraint on cleavage and ductile fracture toughness using area contour toughness scaling
}

DOI:

10.1016/j.engfracmech.2017.09.029

\section{Document Version}

Accepted author manuscript

Link to publication record in Manchester Research Explorer

\section{Citation for published version (APA):}

Seal, C. K., \& Sherry, A. H. (2017). Predicting the effect of constraint on cleavage and ductile fracture toughness using area contour toughness scaling. Engineering Fracture Mechanics, 186, 347-367.

https://doi.org/10.1016/j.engfracmech.2017.09.029

\section{Published in:}

Engineering Fracture Mechanics

\section{Citing this paper}

Please note that where the full-text provided on Manchester Research Explorer is the Author Accepted Manuscript or Proof version this may differ from the final Published version. If citing, it is advised that you check and use the publisher's definitive version.

\section{General rights}

Copyright and moral rights for the publications made accessible in the Research Explorer are retained by the authors and/or other copyright owners and it is a condition of accessing publications that users recognise and abide by the legal requirements associated with these rights.

\section{Takedown policy}

If you believe that this document breaches copyright please refer to the University of Manchester's Takedown Procedures [http://man.ac.uk/04Y6Bo] or contact uml.scholarlycommunications@manchester.ac.uk providing relevant details, so we can investigate your claim.

\section{OPEN ACCESS}




\section{Accepted Manuscript}

Predicting the effect of constraint on cleavage and ductile fracture toughness using area contour toughness scaling

C.K. Seal, A.H. Sherry

PII:

S0013-7944(17)30642-2

DOI: https://doi.org/10.1016/j.engfracmech.2017.09.029

Reference: EFM 5700

To appear in:

Engineering Fracture Mechanics

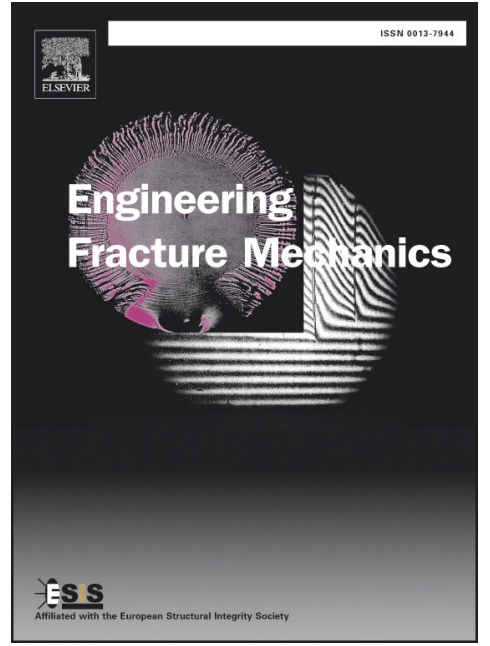

Received Date: $\quad 27$ June 2017

Accepted Date: $\quad 29$ September 2017

Please cite this article as: Seal, C.K., Sherry, A.H., Predicting the effect of constraint on cleavage and ductile fracture toughness using area contour toughness scaling, Engineering Fracture Mechanics (2017), doi: https://doi.org/ 10.1016/j.engfracmech.2017.09.029

This is a PDF file of an unedited manuscript that has been accepted for publication. As a service to our customers we are providing this early version of the manuscript. The manuscript will undergo copyediting, typesetting, and review of the resulting proof before it is published in its final form. Please note that during the production process errors may be discovered which could affect the content, and all legal disclaimers that apply to the journal pertain. 


\title{
Predicting the effect of constraint on cleavage and ductile fracture toughness using area contour toughness scaling
}

\author{
C.K. Seal ${ }^{\mathrm{a}}$, A.H. Sherry ${ }^{\mathrm{a}, \mathrm{b}}$ \\ ${ }^{a}$ University of Manchester, Oxford Road, Manchester, M13 9PL \\ ${ }^{b}$ National Nuclear Laboratory Limited, Chadwick House, Birchwood Park, Warrington, \\ WA3 $6 A E$
}

\begin{abstract}
The influence of constraint on the fracture toughness properties of materials containing defects has long been recognised. To maintain conservative design and assessment principles, lower bound measurements of fracture properties are commonly used. These are measured using test pieces with a high crack tip constraint. With more accurate design processes and tools becoming more widespread, there is a move toward using more representative properties than these lower bound values. The work presented provides a method that can be used to predict the influence of constraint on the cleavage and ductile fracture toughness of a range of ferritic steels, and hence the associated benefit to the onset upper shelf temperature, defined here as the intersection between the fracture toughness loci associated with $5 \%$ cleavage fracture and a $50 \%$ ductile initiation probability.

The Anderson and Dodds toughness scaling procedure, based on the maximum principal stress, has been used with a range of normalised material tensile properties to generate solutions that allow the constraint benefit to cleavage fracture toughness to be predicted for different ferritic steels. A comparison of predictions with published data shows that this results in conservative predictions, similar to those using the Beremin Weibull stress.
\end{abstract}

For the purposes of predicting constraint benefits to ductile initiation tough-

Email address: christopher.seal@manchester.ac.uk (C.K. Seal) 
ness, defined at $0.2 \mathrm{~mm}$ stable tearing, the scaling method proposed by Anderson and Dodds was extended to the Rice and Tracey model as a way to provide solutions for the same matrix of tensile properties. This approach was validated against literature data for constraint effects on ductile initiation.

Finally, a worked example is provided, showing how the influence of crack tip constraint on the onset upper shelf temperature can be predicted using the solutions provided.

Keywords: Constraint, Fracture toughness, Cleavage, Ductile, Onset of upper shelf temperature

\section{List of Symbols}

Latin Characters

a Effective crack length

$A, B, C \quad$ Constants

$A^{C} \quad$ Area enclosed by isostress contour for low constraint specimen

$A^{S S Y} \quad$ Area enclosed by isostress contour for high constraint (small scale yielding) specimen

$C_{i j}, D_{i \hat{\jmath}} \quad$ Parameters for general solutions to $\alpha$ and $k$ respectively

$E \quad$ Young's modulus

G Shear modulus

$J \quad J$ integral

$J_{E s t} \quad$ Estimate of $J$ for a given time increment

$J_{\text {Max }} \quad$ Maximum applied $J$ for finite element model

$J_{\text {Mat }} \quad$ Critical $J$ for high constraint specimen 


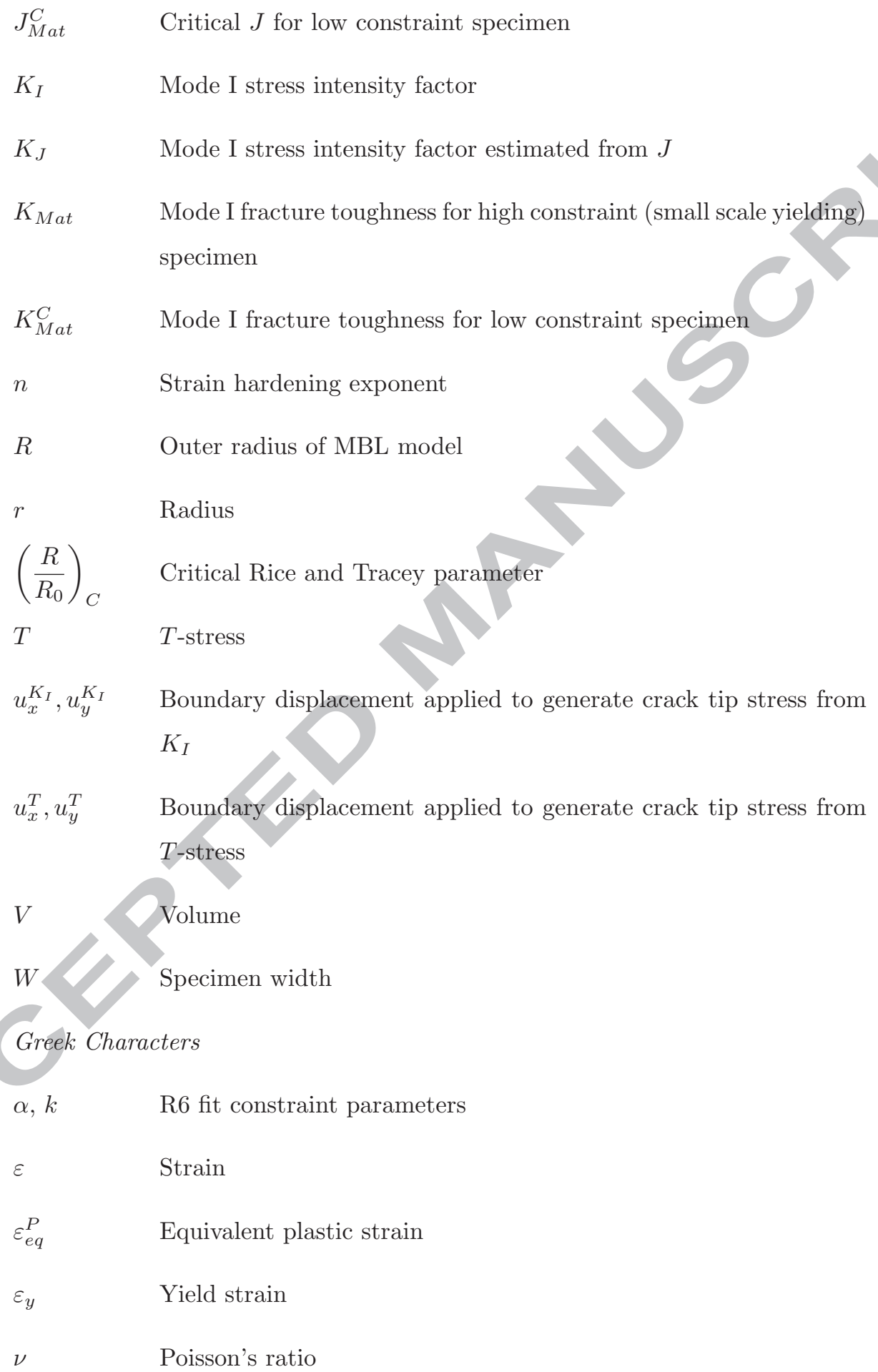




$\begin{array}{ll}\rho & \text { Crack tip radius } \\ \sigma & \text { Stress } \\ \sigma_{e q} & \text { Equivalent flow stress } \\ \sigma_{i j} & \text { The stress component in the } i, j \text { direction } \\ \sigma_{m} & \text { Hydrostatic stress } \\ \sigma_{\text {Max }} & \text { Maximum principal stress } \\ \sigma_{y} & \text { Yield stress } \\ \theta & \text { Angle } \\ \tau_{\text {Inc }} & \text { Current time increment in finite element model } \\ \tau_{\text {Total }} & \text { Total step time for finite element model }\end{array}$

\section{Introduction}

Ferritic steels undergo a transition in fracture mechanism with change in temperature. At low temperatures, fracture proceeds by a cleavage mechanism, in which fracture occurs rapidly by the initiation and catastrophic propagation of a crack along crystallographic planes. Cleavage initiates at microcracks resulting from secondary phase particles within plastically deformed material. It is stochastic in nature and failure occurs when the first critically sized microcrack propagates. This statistical nature of cleavage fracture is best represented by a 'weakest link' model and can be described by a Weibull distribution, where the distribution of secondary phase particles is represented by the shape factor of the distribution (Weibull modulus). The driving force for crack initiation is the crack opening stress the particle experiences $<1>$, and the scaling factor for the probability distribution is, therefore, a function of the crack tip stress field.

By considering the volume of material ahead of a crack exposed to the critical value of opening stress or higher, and the distribution of particles within the 
steel, a probability of cleavage can be determined. This concept underpins the widely used Beremin $<2>$ model for predicting cleavage. It is also used in the Anderson and Dodds $<3>$ and Nevalainen and Dodds $<4>$ toughness scaling models, whereby the predicted probability of cleavage for a given geometry is considered to be equal to a different geometry provided the volume of stressed material is the same.

The assumption of 'weakest link' statistics becomes less representative of the mechanism of failure as the temperature increases and the size of the plastic zone likewise increases. At higher temperatures, fracture occurs as the result of the initiation, growth and coalescence of voids that form around secondary phase particles, such as inclusions or carbides. Under most circumstances, this fracture mechanism is stable, requiring increasing load or displacement to progress. Rice and Tracey $<5>$ proposed a model in which a void grows as a result of plasticity until it reaches a critical size. The ratio of the critical void size to its initial size is considered a material property defining fracture.

Ductile fracture toughness is characterised by a $J-R$ curve, in which the crack driving force, $J$, needed to grow the crack is plotted as a function of crack extension. In ductile steels this curve displays a rising $J$ with increasing crack growth.

The onset of upper shelf temperature (OUST) is a temperature that is defined, such that, above this temperature a ferritic steel can be considered to be on the 'upper shelf' of the fracture toughness transition curve. One approach to defining the OUST is the temperature at which the fracture toughness correlating with a given probability of cleavage (typically $5 \%$ ) intersects with the fracture toughness corresponding to a given amount of ductile tearing (typically $0.2 \mathrm{~mm})<6>$. Figure 1 shows a schematic of a typical ferritic steel fracture toughness transition curve. On this schematic, the 'upper shelf' is the mean ductile initiation fracture toughness (the solid line). The interception with the $5 \%$ cleavage probability toughness line is the OUST.

Once defined, the OUST is then used as the basis for mandated operating conditions where safe operating is of paramount concern. Such is the case in the 
nuclear power generation industry, where the consequences of structural failure in critical components such as the ferritic steel reactor pressure vessel would be unacceptable.

Typically, fracture toughness properties of structural materials are measured using highly constrained test specimen geometries (to the point that additional side grooves can be added to enhance crack tip constraint) as this leads to a conservative, lower bound, measurement of fracture toughness. With the advent of more advanced modelling techniques and plant inspection techniques, it is prudent to quantify this conservatism for real or postulated defects present in service which are typically of lower constraint due to their size relative to the structural geometry or the mode of loading.

One area in which there is scope for improved understanding and tools for predicting the fracture properties is the influence that the state of constraint has on the OUST.

Predicting the effect of constraint on cleavage and ductile fracture toughness, and therefore on the OUST, requires a means of assessing the change of the probability of cleavage and the ductile initiation toughness associated with the state of constraint. Traditionally, highly constrained test pieces, tested over a range of temperatures, are used to provide the fracture toughness data that are analysed to define a conservative estimate of the OUST $<6>$. However, it is economically unfeasible to test all possible states of constraint to determine the constraint effect on OUST. Therefore, it is desirable for a model to be developed that can leverage the available data and scale it according to the state of constraint in a real defect.

The paper is structured as follows. The area contour toughness scaling approach is described first. This is followed by a description of the methodology used in this work, the results of this methodology, and a discussion of these results. Finally conclusions are drawn. 


\section{Area contour toughness scaling}

A toughness scaling model was proposed by Anderson and Dodds $<3>$ and this method has been used in the current work. Furthermore, the methodology proposed by Anderson and Dodds has been extended into the realm of ductile initiation by considering how the area contours of different critical Rice and Tracey parameters are affected by the constraint state.

\subsection{Anderson and Dodds contour method for cleavage}

Cleavage failure follows a probabilistic mechanism, best described by a 'weakest link' model. In this model failure is predicted when the first particle in a distribution of defects fails (much as a chain can be expected to fail when the weakest link fails). Anderson and Dodds recognised that, given the same defect distribution, it follows that the probability of sampling a critical microstructural feature is dependant on the volume of material subjected to its critical stress, such that the probability of failure, $F$, can be expressed in a general form as $<3>$ :

$$
F=f[\sigma, V(\sigma)]
$$

where $V$ is the volume enclosed by an isostress contour for a maximum principal stress, $\sigma_{\text {Max }}$, equal to a given value.

For plane strain loading conditions, the volume term in Equation 1 is proportional to the area defined by the isostress contour equal to $\sigma$. This allows the use of $2 \mathrm{D}$ finite element analysis using plane strain elements to quantify the benefit to cleavage fracture toughness that can be gained due to a loss of constraint.

It must be noted at this point, however, that the use of $2 \mathrm{D}$ analysis is limited to considering only in-plane constraint effects. Significant out-of-plane effects may be present, as discussed by Horn et al $<7>$, which are not accounted for using this method. In cases where there is the expectation that out-of-plane constraint effects will be large, the volume approach proposed by Nevalainen and Dodds $<4>$ can be used. 
Anderson and Dodds showed that, for different constraint states, the stress contours could be scaled by their respective areas and would map closely onto each other. This, in turn, shows that the stress state for different states of constraint can be likewise scaled by their respective areas. Following on from Equation 1 it, therefore, stands to reason that the probability of cleavage failure can also be scaled this way.

Essentially, Anderson and Dodds $<3>$ propose that the probability of cleavage occurring in a specimen with reduced constraint is equal to that of a highly constrained specimen, provided that their volumes (and by extension for plane strain, areas) of critical stress are the same.

On the basis of this concept, $J_{M a t}$ for a high constraint specimen can be correlated with an equivalent $J_{M a t}^{C}$ for a low constraint structure by identifying the load at which the volumes enclosed by an isostress contour of a constant stress is the same. Conversely, given the quadratic relationship between $J$ and the resultant area (discussed in detail by Anderson and Dodds $<3>$ ), for a given load, the ratio of $J$ for low constraint to $J$ for high constraint is given by Equation 2.

$$
\frac{J_{M a t}^{C}}{J_{M a t}}=\sqrt{\frac{A^{S S Y}}{A^{C}}}
$$

where $A^{S S Y}$ is the area enclosed by an iso-stress contour for a high constraint, small scale yielding model, and $A^{C}$ is the area enclosed by the same iso-stress contour for the low constraint model.

\subsection{Use of the contour method with the Rice and Tracey/Beremin model}

A common model for predicting crack initiation and growth is the Rice and Tracey model $<5>$, as modified by Beremin $<8>$, which is based on the concept of void growth up to a critical size. The Rice and Tracey model predicts that void growth rate is a function of the stress state and plastic strain increment, and that the critical void size is a material property. This modified model is described by Equation $3<9>$. 


$$
\ln \left(\frac{R}{R_{0}}\right)_{C}=\int_{\varepsilon_{0}=0}^{\varepsilon_{c}} 0.283 \exp \left(\frac{3 \sigma_{m}}{2 \sigma_{e q}}\right) d \varepsilon_{e q}^{p}
$$

where $\sigma_{m}$ is the hydrostatic stress, $\sigma_{e q}$ is the equivalent flow stress and $\varepsilon_{e q}^{p}$ is the equivalent plastic strain.

The Rice and Tracey parameter is assumed to have a critical value which is a material property. This can be obtained from notched bar specimens in which the fracture strain and stress triaxiality can be determined.

Taking the Anderson and Dodds approach, at the onset of fracture, in a high constraint geometry, the area enclosed by the contour at the critical Rice and Tracey parameter can be determined. For a low constraint structure, fracture is predicted when an equivalent area is enclosed by the same critical Rice and Tracey parameter. Thus, for a low constraint structure, a prediction can be made for $J$ and the benefit to the ductile initiation fracture toughness estimated.

The need to know the critical void growth is a limiting factor when providing solutions for a wide range of different materials. This limitation can be overcome by using an equivalent toughness scaling method to that proposed by Anderson and Dodds for cleavage, but taking contours of equal void growth ratios.

If the areas defined by different Rice and Tracey contours can be shown to scale proportionally in both the low and high constraint cases, then the ratio of the 'effective' fracture toughness for a low constraint structure to the high constraint toughness is independent of the Rice and Tracey parameter chosen. As a result, the toughness benefit can be applied without the necessity of knowing the critical Rice and Tracey parameter for the material of interest.

\section{Methodology}

\subsection{Modified Boundary Layer model}

Modified boundary layer (MBL) models are a well-tested, convenient way of testing a range of different constraint states within a single model. As such, MBL models are well suited to parametric studies, such as the one presented. 
An MBL model is one in which a crack is introduced to an effectively infinite plate. Typically they are circular or semi-circular with a radius, $R$, being at least $10^{5}$ times larger than the crack tip dimension $\rho$. In the case of the model used in this study, $\rho=25 \mu \mathrm{m}$ and $R=2.5 \mathrm{~m}$.

A semi-circular MBL model, taking advantage of symmetry along the crack ligament, was developed in $\mathrm{ABAQUS}^{\mathrm{TM}}$ finite element analysis software. Four node, plane strain elements (ABAQUS ${ }^{\mathrm{TM}}$ type CPE4) were used, with a bias towards smaller elements at the crack tip. Large strain analyses were used to accommodate the changes in crack tip geometry due to the magnitude of the applied load. Figure 2 shows the details of the crack tip mesh.

Williams $<10>$ defined the elastic stress field ahead of a crack tip using a power series expansion of the form given in Equation $4<11>$.

$$
\sigma=\frac{A(\theta)}{\sqrt{r}}+B(\theta)+C(\theta)^{1 / 2}+\ldots
$$

where $\sigma$ is the stress, $A, B$, and $C$ are the values defining the stress state, and $r, \theta$ are polar coordinates defining a point in the vicinity of the crack tip.

When expressed in matrix notation, Equation 4 takes the form shown in Equation $5<12>$, in which $K_{I}$ is the mode I stress intensity factor and $T$ is the so-called $T$-stress.

$$
\left.\sigma_{i j}=\frac{K_{I}}{\sqrt{2 \pi r}} f_{i j}(\theta)\right)+\left[\begin{array}{ccc}
T & 0 & 0 \\
0 & 0 & 0 \\
0 & 0 & \nu T
\end{array}\right]+\ldots
$$

where $\sigma_{i j}$ is the stress component in the $i, j$ direction, and $\nu$ is Poisson's ratio.

Typically, in linear elastic fracture mechanics, the first, $K_{I}$ term is assumed to be dominant and the rest of the expansion is ignored $<13>$. The second term of the expansion, the $T$-stress, has the effect of changing the constraint state at the crack tip, with compressive $T$-stresses reducing crack tip constraint.

In a MBL model, the crack tip stress is induced by applying a displacement boundary condition at the edge of the model. This displacement is defined in 
terms of radial coordinates where $R$ is the radius of the MBL model and $\theta$ is the angle measured counterclockwise from directly ahead of the crack tip ${ }^{1}$.

For plane strain conditions, the displacement fields can be written in terms of the Young's modulus, $E$ as Equations 6 and 7

$$
\begin{aligned}
u_{x}^{K_{I}} & =K_{I} \frac{1+\nu}{E} \sqrt{\frac{R}{2 \pi}} \cos \left(\frac{\theta}{2}\right)[3-4 \nu-\cos (\theta)] \\
u_{x}^{T} & =\frac{1-\nu^{2}}{E} R T \cos (\theta) \\
u_{y}^{K_{I}} & =K_{I} \frac{1+\nu}{E} \sqrt{\frac{R}{2 \pi}} \sin \left(\frac{\theta}{2}\right)[3-4 \nu-\cos (\theta)] \\
u_{y}^{T} & =-\frac{\nu(1+\nu)}{E} R T \sin (\theta)
\end{aligned}
$$

In all cases, the $T$-stress displacement was applied first ensuring that for each load increment a constant $T$-stress was present. It should be noted that does not represent typical loading conditions in service, where the $T$-stress will increase with increasing load applied to the defect. The influence of this constraint history will be discussed.

\subsubsection{Material properties}

Tensile material properties were selected for a parametric study of the influence of $T$-stress on the OUST. The properties used are defined in terms of a normalised yield stress, $E / \sigma_{y}$, and a strain hardening coefficient, $n$, according to Equation 8

$$
\frac{\varepsilon}{\varepsilon_{y}}= \begin{cases}\frac{\sigma}{\sigma_{y}} & \text { where } \varepsilon \leq \varepsilon_{y} \\ \left(\frac{\sigma}{\sigma_{y}}\right)^{n} & \text { where } \varepsilon>\varepsilon_{y}\end{cases}
$$

where $\varepsilon$ is the strain at stress $\sigma$, and $\sigma_{y}$ and $\varepsilon_{y}$ are the yield stress and strain respectively.

\footnotetext{
${ }^{1}$ The crack tip is assumed to lie on the $\mathrm{X}$ plane, with crack opening stresses acting in the $\mathrm{Y}$ direction. If the orientation differs then the displacements will likewise differ.
} 
The analysis was carried out using a range of material properties that represent a wide range of ferritic steels and are based on the values present by Sherry et al. $<14>$. Table 1 shows the range of properties tested.

\subsubsection{Calculation of the Rice and Tracey parameter}

A user variable $\left(\right.$ ABAQUS $^{\mathrm{TM}}$ UVARM) subroutine was defined to calculate the Rice and Tracey parameter for each integration point using Equation 3. Contours of constant Rice and Tracey parameters were constructed using ABAQUS ${ }^{\mathrm{TM}}$ taking advantage of the in-built interpolation routines. These contours were then analysed in the same way as the stress contours.

\subsubsection{Calculation of the contour areas}

The area defined by the isostress and Rice and Tracey contours was calculated automatically. An image of the contour of interest was exported using Wavefront OBJ image format. This format is a plain text image format that contains details of a surface triangulation which describes the image. Summing the areas of the individual triangles in the surface gave the desired area and this was verified on the basis of element volumes and through the use of a 3rd party image analysis software package $($ MeshLab <15>).

\subsection{R6 two-parameter model}

There is guidance provided in the R6 assessment procedure $<16>$ on an approach to account for constraint using a simple 2-parameter model, based on the work of Ainsworth and O'Dowd $<17>$. With respect to the $T$-stress, the model proposed in R6 is described in Equation 9.

$$
K_{\text {Mat }}^{C}= \begin{cases}K_{\text {Mat }} & \text { where } \frac{T}{\sigma_{y}} \geq 0 \\ K_{\text {Mat }}\left[1+\alpha\left(-\frac{T}{\sigma_{y}}\right)^{k}\right] & \text { where } \frac{T}{\sigma_{y}}<0\end{cases}
$$

This model has the advantage that for a given material, the effect of any state of constraint can be modelled with two parameters, $\alpha$ and $k$. Sherry et al. $<14>$ note that $\alpha$ and $k$ are dependent on the material properties and the 
fracture mechanism, with ductile initiation being less significantly affected than cleavage, thus two sets of parameters are needed to predict the influence of constraint on OUST.

\subsubsection{Determination of $\alpha$ and $k$}

Equation 2 shows that the ratio of $J_{\text {Mat }}^{C}$ to $J_{\text {Mat }}$ can be readily calculated from the areas defined by stress contours of interest. Using the well-known plane strain relationship between $J$ and $K_{I}$ (strictly speaking $K_{J}$ ), shown in Equation 10, then the ratio of $K_{M a t}^{C}$ to $K_{M a t}$ can be calculated from Equation 11

$$
\begin{gathered}
K_{J}=\sqrt{\frac{E J}{1-\nu^{2}}} \\
\frac{K_{M a t}^{C}}{K_{M a t}}=\sqrt{\frac{J_{M a t}^{C}}{J_{M a t}}}=\left(\frac{A^{S S Y}}{A^{C}}\right)^{1 / 4}
\end{gathered}
$$

For each material property combination the following steps were carried out:

1. A MBL model with a $T$-stress equal to 0 was analysed for a series of increasing applied $K$.

2. For a range of $T$-stresses between $-0.1_{y}$ and $-1.0 \times \sigma_{y}$, an MBL model was analysed in which the $T$-stress was applied, followed by the same series of increasing applied $K$ as in step 1.

3. For each value of applied $K$ in the series, the areas enclosed by a number of iso-stress and iso-Rice and Tracey contours were calculated. $A^{S S Y}$ was determined from the analyses with $T$-stress equal to 0 and $A^{c}$ from each of the $T$-stresses in the range tested.

4. The predicted benefit to fracture toughness for both cleavage and ductile initiation was calculated using Equation 11.

For each combination of $T$-stress and material properties, a plot of $K_{M a t}^{c} / K_{M a t}$ vs the applied $K, K_{\text {Applied }}$ was constructed, such as is shown in Figure 3. From Figure 3 it can be seen that the ratio of $K_{\text {Mat }}^{C}$ to $K_{\text {Mat }}$ reaches a constant value at relatively small $K_{\text {Applied }}$. For each set of material properties the value at 
which this ratio becomes constant was plotted against $T / \sigma_{y}$ as shown in Figure 4 .

A curve of the type defined in Equation 9 was fit to the data using the curve_fit routine in Python's Scipy library. Visually, close fits were obtained using Equation 9 and this is reflected in the fit parameters' standard errors, which are relatively small.

\section{Results}

Values of $\alpha$ and $k$ have been tabulated for both cleavage and ductile initiation in the form of look-up tables (Tables 2 and 3 respectively).

In order to facilitate ease of use, a set of functions and tables of their associated coefficients are also included. These enable the calculation of $\alpha$ and $k$ for any combination of $E / \sigma_{y}$ and $n$, within the bounds of validity defined.

\subsection{Look-up tables}

The look-up table for $\alpha$ and $k$ in the case of cleavage is provided in Table 2. Values are provided for $4 \leq n \leq 10$ and a range of $E / \sigma_{y}$ as defined in Table 1. Three different stress contours have been used in the development of this look-up table and the results for $\sigma_{\operatorname{Max}} / \sigma_{y}=2.0,2.5,3.0$ are reported.

A similar look-up table has been constructed for ductile initiation and is reported as Table 3. Values are reported for the same ranges of $n$ and $E / \sigma_{y}$ as the cleavage cases. Contours for four different Rice and Tracey parameters were used to determine $\alpha$ and $k$, specifically $\left(R / R_{0}\right)_{C}=1.02,1.36,2.05,2.73$, which are arbitrary values based on the critical Rice and Tracey parameter for the 'Euro' dataset reported by Rakin et. al. $<18>$.

As will be discussed, the effect of constraint on the ductile initiation toughness is apparently independent of the Rice and Tracey contour chosen and a single curve fit through all data points for the four contours has, therefore, been carried out. As a result, there is only a single set of parameters given for each set of material properties tested. 


\subsection{Parametrised solutions}

Within the bounds of the test matrix laid out in Table 1, a set of parametrised solutions for $\alpha$ and $k$ have been derived for isostress contours of $2.0,2.5 \& 3.0 \times \sigma_{y}$ and for Rice and Tracey contours.

Each contour has been treated separately as it appears that the relationship of $\alpha$ and $k$ with isostress contour is complex and outside the scope of this work.

For each contour a quadratic surface of the form given in Equation 12 provides a reasonable fit to the data, with predicted $\alpha$ and $k$ being within $12 \%$ (the majority of predictions are less than $5 \%$ different) of those calculated from the finite element analysis. For the ductile initiation fits, the parametrised solutions are within $3 \%$ of those calculated from the finite element analysis.

$$
\begin{array}{r}
\alpha=C_{00}+C_{10} n+C_{01}\left(\frac{E}{\sigma_{y}}\right)+C_{11} n\left(\frac{E}{\sigma_{y}}\right)+C_{20} n^{2}+C_{02}\left(\frac{E}{\sigma_{y}}\right)^{2} \\
+C_{21} n^{2}\left(\frac{E}{\sigma_{y}}\right)+C_{12} n\left(\frac{E}{\sigma_{y}}\right)^{2}+C_{22} n^{2}\left(\frac{E}{\sigma_{y}}\right)^{2} \\
k=D_{00}+D_{10} n+D_{01}\left(\frac{E}{\sigma_{y}}\right)+D_{11} n\left(\frac{E}{\sigma_{y}}\right)+D_{20} n^{2}+D_{02}\left(\frac{E}{\sigma_{y}}\right)^{2} \\
+D_{21} n^{2}\left(\frac{E}{\sigma_{y}}\right)+D_{12} n\left(\frac{E}{\sigma_{y}}\right)^{2}+D_{22} n^{2}\left(\frac{E}{\sigma_{y}}\right)^{2}
\end{array}
$$

Table 4 lists the parameters for each isostress contour and for the Rice and Tracey parameter.

\section{Discussion}

5.1. Comments on MBL models

At relatively large values of $J$ there is a risk that the plastic zone is not sufficiently contained within the bounds of the MBL model to ensure that it gives valid results. Typically, a value of $R / 10$ is recommended as the maximum radius for the plastic zone, but this value is heuristic in nature. For the work reported, a value of $R / 5$ has been used. In order to ensure that the results 
obtained were valid, an estimate of the expected value of $J$ was compared with $J$ calculated from the finite element analysis.

An estimate of the expected value of $J$ from the model can be made because the $K_{I}$ displacements have been applied as a linear ramp over a known time increment. From Equations 6 and 7 it can be seen that $K_{I}$ is directly proportional to the applied displacement, thus $K_{I}$ at the crack tip increases linearly over the known time increment also. From Equation 10, $J$ is proportional to $K_{I}^{2}$, thus if the $K_{I}$ displacement is applied linearly then $J$ will increase in a parabolic fashion. As the total time is known and the maximum applied $J$ is likewise known, then an estimate of $J$ for a given increment of time can be calculated from Equation 13

$$
J_{E s t}=J_{M a x} \times\left(\frac{\tau_{\text {Inc }}}{\tau_{\text {Total }}}\right)^{2}
$$

where $J_{E s t}$ and $J_{M a x}$ are the estimated and maximum value of $J$ respectively, and $\tau_{I n c}$ and $\tau_{\text {Max }}$ are the increment of time and the total time respectively.

Plots comparing the value of $J$ calculated from the finite element analysis with this estimation of $J$ were constructed. Figure 5 shows a set of typical plots for a range of $T$-stress. The solid points represent points measured when the size of the plastic zone is smaller than $R / 5$ and are considered 'valid'. When the size of the plastic zone exceeds this limit, then the data points are considered to be 'invalid' and are plotted with hollow symbols.

For a maximum plastic zone size of $R / 5$ both the estimated and measure $J$ vary by less than $5 \%$ which suggests that, in this case, the typical rule of thumb is excessively conservative and $R / 5$ is a reasonable limit to use.

As a further check, a plot of the normalised crack opening stress as a function of normalised distance from the crack tip was generated, such as is shown in Figure 6. As can be seen in Figure 6, the $Q$ parameter, as defined by the difference in the crack opening stress field relative to the high constraint, small scale yielding model (the typical measure of constraint where there is a large amount of plasticity) is equivalent to the $T$-stress. Therefore, the use of $T$-stress 
is an appropriate measure of constraint for these analyses.

The use of Equation 2 to determine the predicted benefit is based on the assumption that the area enclosed by the isostress contour scales quadratically with increasing $J$. On this basis the square root of difference in areas between low and high constraint load conditions at equal $J$ is equivalent to the difference in $J$ at equal areas, as discussed by Anderson and Dodds $<3>$.

In all cases a visually close fit could be seen, such as in Figures 7 and 8 (for iso-stress and iso-Rice and Tracey analyses, respectively), thus ensuring that the results obtained from the reported analyses fit with the quadratic behaviour assumed. On this basis the predicted equivalent $J_{M a t}^{C}$ for a low constraint geometry can be calculated using Equation 2, as per the Anderson and Dodds.

\subsection{Choice of stress contour}

Anderson and Dodds $<3>$ show that there is increasing difference in the ratio of $J_{M a t}^{C}$ to $J_{M a t}$ calculated from different maximum principal stress contours with increasing $J$ and this observation matches well with the results obtained in the work reported here. Unlike the results presented by Anderson and Dodds, in which both low and high stress contours increased the predicted benefit to fracture toughness associated with low constraint, two general trends were observed in the current work:

- The constraint benefit predicted from smaller isostress contours is smaller than the benefit predicted from larger ones.

- Lower strain hardening materials (higher $n$ ) show an enhanced difference between different stress contours. There is also a small effect of yield stress on the difference, with lower yield stresses showing an enhanced difference, but this is significantly smaller than the influence of strain hardening rate.

The influence of the chosen stress contour has yet to be fully explored and, in the absence of more information, the oft-used literature value of $3 \times \sigma_{y}$ is recommended for use. 


\subsection{Rice and Tracey contours}

In contrast to the results observed for different isostress contours, the predicted benefit to ductile initiation fracture toughness from the use of different Rice and Tracey parameter contours is apparently independent of the choice of critical Rice and Tracey parameter. Figure 9 is one such plot for a material with $n=6$ and $E / \sigma_{y}=600$, showing how the predicted benefit, as a function of $T / \sigma_{y}$, for different critical Rice and Tracey parameters overlay one another.

Figure 9 is typical of the observed results across all the material properties tested, which suggests that the benefit to ductile initiation fracture toughness can be predicted from any sensible Rice and Tracey parameter, thus eliminating the need to determine the critical value for the individual steel of interest.

Further experimental validation of this observation is recommended, but a comparison with existing literature $<19-21>$ shows that the predicted benefits to ductile initiation fracture toughness are broadly similar, which suggests that the approach presented is valid.

\subsection{The effect of constraint history}

As described in Section 3.1, displacements were applied to the MBL model in a stepwise manner, with the displacements due to the $T$-stress applied in a separate load step to the $K$ displacement. In practice, a defect under load would experience both $K$ and $T$-stress increasing in proportion to each other.

A number of MBL models were, therefore, run with $K$ and $T$ applied proportionally. Specific increments were identified at which $K$ and the $T$-stress were equivalent to the $K$ and $T$-stress used in the non-proportionally applied load cases. The isostress contours and Rice and Tracey contours at these load increments were extracted and the area enclosed by each calculated and compared to the resulting contours from the non-proportionally applied load cases at equal $J$.

Figures 10 and 11 are typical of the different contours obtained. On the basis of this assessment, the influence of differing load paths is not significant when determining the influence of constraint on the cleavage properties, as evidenced 
by the close match of the iso-stress contours in Figure 10. This is not the case for the contours of fixed Rice and Tracey parameter. Therefore, the loading path needs to be considered when determining any predicted benefit to ductile fracture toughness.

Using a non-proportional load case leads to non-conservative predictions of the benefit to ductile initiation fracture toughness. The difference in predicted fracture properties between non-proportional and proportional load cases appears to increase in an approximately linear manner with reducing constraint. For the cases assessed, this difference typically rises to a maximum of the order of $20 \%$.

On reflection, this is not an unexpected result. The presence of a hydrostatic stress field has been shown to accelerate the growth of voids as discussed by Rice and Tracey $<5>$. Where there is initially a relatively highly constrained defect, such as would be expected in a MBL model at a low applied $K$, the void growth is enhanced, such that, when the constraint state of the model loaded proportionally approaches the constraint state of an equivalent model in which the constraint state was low throughout the load history, the voids in the proportionally loaded model will be larger.

With this in mind, there is a caveat that must be raised when the lookup tables for ductile fracture are used and at this point in time they should be considered indicative only.

For ductile fracture the constraint history this analysis shows that the load history is an important consideration and its influence needs further research.

5.5. Comparison with existing literature results

\subsubsection{The influence of constraint on cleavage fracture toughness}

Sumpter and Hancock $<22 ; 23>$ carried out a series of fracture toughness tests for different states of constraint and plotted the measured toughness against $\frac{T}{\sigma_{y}}$.

Sherry et. al. $<14>$ report the data produced by Sumpter and Hancock and included fitted parameters for an R6 two parameter estimate of the benefit 
gained to lower bound fracture toughness as a function of constraint. Following this methodology, an R6 two parameter fit through the data, rather than a lower bound fit, has been used to compare the predicted benefit to cleavage resulting from the analysis using the Anderson and Dodds toughness scaling approach.

Given the observed differences in the predicted benefit to cleavage toughness with different stress contours, the value of $\sigma_{M a x} / \sigma_{y}=3.0$ has been used for the comparison. This is toward the higher end of stress contour for which their was a 'measurable' value and thus represents one of the less conservative predictions.

The yield strength and strain hardening coefficients are reported by Sherry et. al. $<14>$ as $\approx 275 M P a$ and 5 , respectively. This corresponds to $n=5$ and $\frac{E}{\sigma_{y}}=750$.

Figure 12 is a plot of the test data, the experimentally fit R6 curve and the predictions for the benefit to fracture toughness made using the Anderson and Dodds toughness scaling method, with a $\sigma_{M a x} / \sigma_{y}=3.0$. Based on this plot, it can be seen that the predictions made using the Anderson and Dodds toughness scaling method are conservative with respect to the data and are similar to those made using the Beremin-Weibull stress method $<14>$.

\subsubsection{The influence of constraint on ductile initiation}

Hancock et. al. $<19>$ show the results of experimental testing, correlating the influence of constraint, as characterised by $T$-stress with changes in $J$ for differing levels of ductile tearing. Data presented by Hancock et. al. $<19>$ have been used to compare the result of experimental testing with the prediction of benefit obtained using the Rice and Tracey contour method used in this work.

Table 5 shows the values extracted from Figure 13. in Hancock et. al. $<19>$ and are the data points for $0.2 \mathrm{~mm}$ of crack growth. The data points for positive $T$-stress were not accounted for in this analysis as these give a value of unity when fit to the R6 two parameter fit, shown in Equation 9.

The data in Table 5 were plotted and a fit to the R6 two parameter model. This was then compared with the predicted benefit to ductile initiation using the Rice and Tracey contour method described. Figure 13 shows the result of 
this comparison. Since the reported strain hardening rate is "close to $10 "<19>$, $n$ 's of 9 and 10 have been used for the comparison. Similarly, since the reported yield stress, $470 M P a<19>$, is close to $E / \sigma_{y}=450$, this value of normalised yield stress has been used.

On the basis of this plot it seems that the predicted benefit to ductile initiation is similar to the experimental results for $0.2 \mathrm{~mm}$ of ductile tearing which suggests that the presented approach is valid. This result is tempered by the knowledge that the loading path has an effect on the predicted benefit, as discussed in Section 5.4. Given the observed maximum is in the order of $20 \%$ difference, then this suggests that the predicted benefit, should the constraint history be taken into account, would be more representative of a lower bound estimate of the literature data.

\subsubsection{Comparison with Weibull stress method}

Sherry et. al. $<14>$ provide look up tables to account for the change in cleavage fracture toughness resulting from reduced constraint. These look up tables provide parameters in the same way as the current work does, except that the analysis is based on the Beremin Weibull stress model $<2>$.

A comparison between the predicted benefit to cleavage toughness has been made between these two models. This was carried out by plotting the predicted benefit as a function of $T / \sigma_{y}$, using the R6 parameters from both models (the Weibull stress, and Anderson and Dodds approaches), and was carried out for all values of $E / \sigma_{y}$ and $n$ that were in common in the two bodies of work. For the purposes of the Weibull stress model, $m$ values of $5,10,15 \& 20$ were chosen to give a representative comparison over the complete range of Weibull moduli considered. Figure 14 shows a typical plot of the two different models.

Based on an analysis of each of the materials trialled, it can be concluded that the results obtained by each method are comparable with similar results generated. 


\subsection{Predicting the OUST}

The R6 parameters presented in this work can be used to determine the effect that constraint has on the OUST through shifting the transition curve and the upper shelf. In order to do so a series of finite element analyses need to be carried out, modelling the defect of interest, using material properties relevant to the temperature range of interest.

In the first case an elastic analysis needs to be carried out to determine the relationship between the applied load and the $T$-stress. Alternatively, tabulated data such as that provided by Sherry et. al. $<24>$ in the form of a compendium of $T$-stress solutions can be used. Elastic plastic analyses at different temperatures (represented by different material properties) are then carried out and the toughness scaled using the Anderson and Dodds approach.

Using the load vs $T$-stress relationship obtained from the elastic analysis, $T$-stress trajectories can be plotted against the R6 benefit to cleavage toughness curve. The intersection of these two curves is the predicted point of fracture. Using this point, a prediction for the benefit to cleavage toughness can be made for each temperature. This in turn allows the shift in the transition curve to be predicted.

A similar analysis can be carried out for the ductile initiation fracture toughness, which allows a shift in the upper shelf to be estimated.

The modified transition curve and upper shelf can then be replotted and the OUST estimated from their intersection.

\subsubsection{Example analysis}

In order to illustrate this approach, an example analysis has been carried out for a shallow cracked $(a / W=0.1)$, three point bend test specimen using the 'Euro' dataset $<25>$ as the high constraint reference. Temperature dependent stress strain curves were estimated and fit to the normalised material properties presented in this work. On the basis of a least squares minimisation, the best fits to the normalised material properties are:

- $n=7$ and $E / \sigma_{y}=500$ for temperatures from $-60^{\circ} \mathrm{C}$ to $20^{\circ} \mathrm{C}$. 
- $n=7$ and $E / \sigma_{y}=450$ for temperatures from $-100^{\circ} \mathrm{C}$ to $-60^{\circ} \mathrm{C}$.

For each of the temperatures shown in Table 6, an estimate of the lower bound ( $5 \%$ probability of cleavage) fracture toughness was made on the basis of a censored Weibull fit. These fracture toughness data were used as the high constraint baseline toughness that formed the basis for scaling. For ductile initiation, the upper shelf initiation fracture toughness of $325 M P a \sqrt{m}$ was estimated from the raw data.

Using the temperature dependent stress strain curves, 2D plane strain finite element analyses of the three point bend test specimen were carried out. Isostress contours at $3.0 \times \sigma_{y}$ were constructed and the area enclosed calculated as a function of $J$, while the plastic zone was constrained. The area was then used to scale the toughness using the Anderson and Dodds approach, giving a prediction of the benefit to the fracture toughness. It should be noted that, given the scarcity of data available at $-10^{\circ} \mathrm{C}$ a good estimate of the fracture toughness for a $5 \%$ probability of cleavage could not be made. Accordingly, this temperature is missing from the analysis. In a similar vein, the data at $-60^{\circ} \mathrm{C}$ is known to include a number of tests with a higher fracture toughness $<25>$ and thus the data at the temperature was weighted with a lower weighting when fitting the fracture toughness curve.

$T$-stress trajectories were constructed for both $5 \%$ probability of cleavage toughness and ductile initiation fracture toughness as shown in Figures 15 and 16. In the case of the cleavage trajectory at $20^{\circ} \mathrm{C}$, the plastic zone became unconstrained before $J$ became large enough to get a good estimate of the benefit gained. To compensate for this limitation, the $T$-stress trajectory was extrapolated.

On the basis of the predicted benefits the transition curve and upper shelf were scaled and the plot shown in Figure 17. From this analysis, the predicted OUST is $1^{\circ} \mathrm{C}$, a shift of $10^{\circ} \mathrm{C}$ from the high constraint OUST.

This estimate of the predicted benefit to OUST is counterintuitively, conservative. The conservatism in the analysis is due to the non-conservatism in 
the estimate of the upper shelf fracture toughness. Given that OUST is defined by the intersection of the cleavage fracture toughness locus and the upper shelf, an increase in the upper shelf toughness has the effect of shifting the OUST to higher temperatures.

\section{Conclusions}

On the basis of the work described in this paper, the following conclusions have been drawn.

1. A method for predicting the influence of constraint on both cleavage and ductile initiation fracture toughness, and hence the OUST, has been proposed and sample analyses carried out.

2. Look-up tables for the R6 constraint parameters ( $\alpha$ and $k$ ) have been constructed for both cleavage and ductile initiation, as a function of $T$ stress.

3. Parametrised solutions for $\alpha$ and $k$ have been generated and are relevant within the bounds of the material properties referenced. Coefficients for these solutions are provided for each of the isostress contours used to predict cleavage fracture toughness as well as for the Rice and Tracey contours used to predict ductile initiation fracture toughness.

4. The constraint history has been shown to have no influence on the predicted benefit to cleavage fracture toughness, but to have up to a $20 \%$ influence on the predicted benefit to the ductile initiation fracture toughness.

5. Specific observations have been made for the cleavage models:

(a) The Anderson and Dodds toughness scaling method is practical and conservative, leading to predictions that are similar to the Beremin Weibull stress model.

(b) The choice of stress contour is an important consideration when carrying out this type of analysis. Further work is needed to fully understand the influence this plays. 
6. The Anderson and Dodds scaling approach has been extended to use with the Rice and Tracey parameter. This method eliminates the need to know the specific critical Rice and Tracey parameter for the material in question.

\section{Acknowledgements}

Funding for this research was provided by Rolls-Royce. The authors would like to thank Dr. Rob McClusky (Siemens Industrial Turbine Company (UK)), Dr. Dan Cogswell (Rolls-Royce) and Dr. David Beardsmore (Amec Foster Wheeler) for their assistance during this work.

\section{References}

[1] R. O. Ritchie, J. F. Knott, J. R. Rice, On the relationship between critical tensile stress and fracture toughness in mild steel, J. Mech. Phys. Solids 21 (6) (1973) 395-410.

[2] F. M. Beremin, A. Pineau, F. Mudry, J.-C. Devaux, Y. D'Escatha, P. Ledermann, A local criterion for cleavage fracture of a nuclear pressure vessel steel, Metall. Trans. A 14 (11) (1983) 2277-2287.

[3] T. L. Anderson, R. H. Dodds, Specimen Size Requirements for FractureToughness Testing in the Transition Region, J. Test. Eval. 19 (2) (1991) $123-134$.

[4] M. Nevalainen, R. H. Dodds Jr., Numerical investigation of 3-D constraint effects on brittle fracture in SE (B) and C (T) specimens, Int. J. Fract. 74 (1995) 131-161.

[5] J. Rice, D. Tracey, On the ductile enlargement of voids in triaxial stress fields, J. Mech. Phys. Solids 17 (3) (1969) 201-217.

[6] F. Burdekin, D. Lidbury, R. Moskovic, On the onset of upper shelf transition temperature behaviour in ferritic steels, Int. J. Press. Vessel. Pip. 76 (13) (1999) 875-877. 
[7] A. Horn, A. Sherry, P. Budden, Size and geometry effects in notched compact tension specimens, International Journal of Pressure Vessels and Piping 154 (2017) 29-40.

[8] F. M. Beremin, Cavity formation from inclusions in ductile fracture of A508 steel, Metall. Trans. A 12 (5) (1981) 723-731.

[9] M. Rakin, Numerical Modeling of Ductile Fracture Initiation in Structural Steel, Factas Univ. Mech. Eng. 1 (8) (2001) 939-946.

[10] M. Williams, On the stress distribution at the base of a stationary crack, J. Appl. Mech. 24 (1957) 109-114.

[11] D. J. Unger, Analytical Fracture Mechanics, Dover Publications Inc., 31 East 2nd Street, Mineola, NY, 2001.

[12] M. Verstraete, W. D. Waele, Development and Validation of a High Constraint Modified Boundary Layer Finite Element Model, Sustain. Constr. Des. (2) (2011) 228-236.

[13] Z. Z. Du, J. W. Hancock, The effect of non-singular stresses on crack-tip constraint, J. Mech. Phys. Solids 39 (4) (1991) 555-567.

[14] A. H. Sherry, M. A. Wilkes, D. W. Beardsmore, D. P. G. Lidbury, Material constraint parameters for the assessment of shallow defects in structural components Part I : Parameter solutions, Eng. Fract. Mech. 72 (2005) $2373-2395$.

[15] P. Cignoni, M. Callieri, M. Corsini, M. Dellepiane, F. Ganovelli, G. Ranzuglia, MeshLab: an Open-Source Mesh Processing Tool, in: V. Scarano, R. D. Chiara, U. Erra (Eds.), Eurographics Italian Chapter Conference, The Eurographics Association, 2008.

[16] R6, Revision 4, with updates to Amendment 11, Assessment of the integrity of structures containing defects., EDF Energy, Glouster, UK (2015). 
[17] R. Ainsworth, N. O'Dowd, Constraint in the Failure Assessment Diagram Approach for Fracture Assessment, J. Press. Vessel Technol. 117 (1995) $260-267$.

[18] M. Rakin, A. Sedmak, P. Matejic, M. Zrilic, S. Sedmak, Numerical Simulation of Ductile Fracture Initiation By Application of Rice-Tracey Void Growth Model, in: ECF13 Eur. Conf. Fract., San Sebastian, Spain, 2000, p. 1.

[19] J. Hancock, W. Reuter, D. Parks, Constraint and Toughness Parameterized by T, in: E. Hackett, K.-H. Schwalbe, R. Dodds (Eds.), Constraint Eff. Fract. (ASTM STP 1171), American Society for Testing and Materials (ASTM), Philadelphia, 1993, pp. 21-40.

[20] N. O. Larrosa, R. A. Ainsworth, Ductile fracture modelling and J-Q fracture mechanics: a constraint based fracture assessment approach, Frat. ed Integrita Strutt. 38 (2016) 266-272.

[21] J.-S. Kim, N. Larrosa, A. Horn, Y.-J. Kim, R. Ainsworth, Notch bluntness effects on fracture toughness of a modified S690 steel at 150C, Engineering Fracture Mechanics (in press).

[22] J. D. G. Sumpter, J. W. Hancock, Shallow crack toughness of HY80 welds. An analysis based on T stresses, Int. J. Press. Vessel. Pip. 45 (2) (1991) $207-221$.

[23] J. D. G. Sumpter, J. W. Hancock, An experimental investigation of the T-stress approach., in: E. Hackett, K.-H. Schwalbe, R. Dodds (Eds.), Constraint Eff. Fract. (ASTM STP 1171), American Society for Testing and Materials (ASTM), Philadelphia, 1993, pp. 492-502.

[24] A. H. Sherry, C. C. France, M. R. Goldthorpe, Compendium of T-Stress Solutions for Two and Three Dimensional Cracked Geometries, Fatigue Fract. Eng. Mater. Struct. 18 (1) (1995) 141-155. 
[25] K. Wallin, Master curve analysis of the "Euro" fracture toughness dataset, Eng. Fract. Mech. 69 (4) (2002) 451-481. 


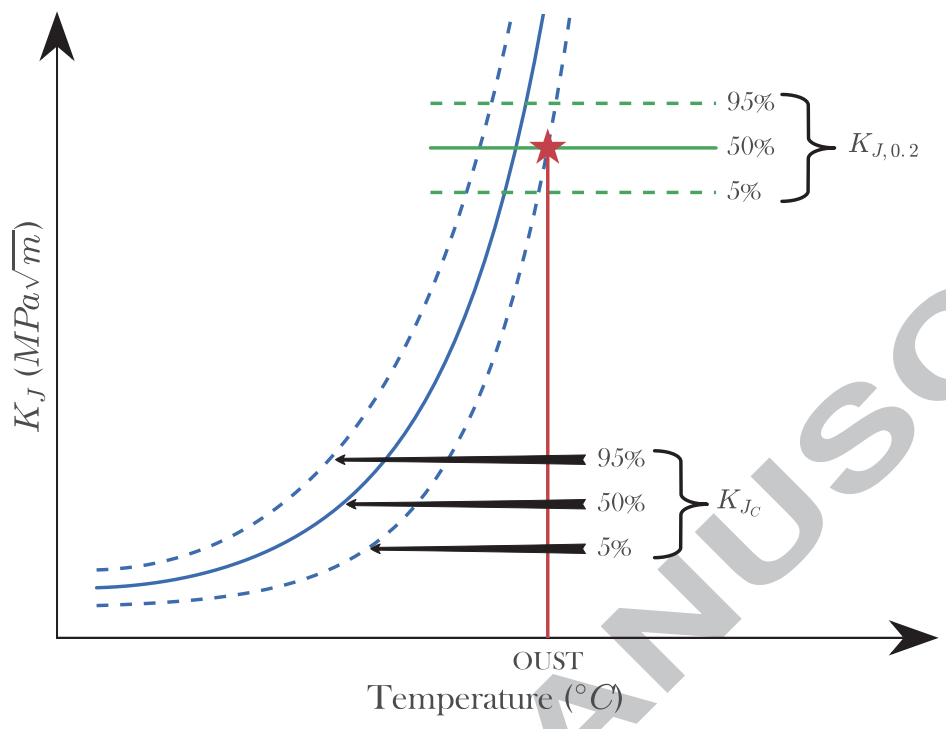

Figure 1: Schematic of a typical ferritic steel ductile to brittle fracture toughness transition curve.

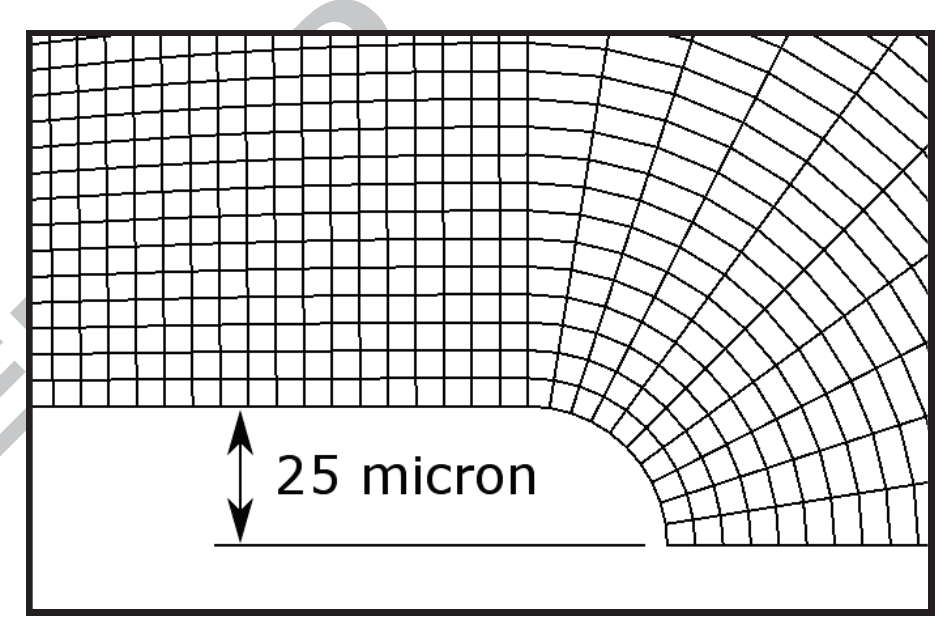

Figure 2: Crack tip mesh 


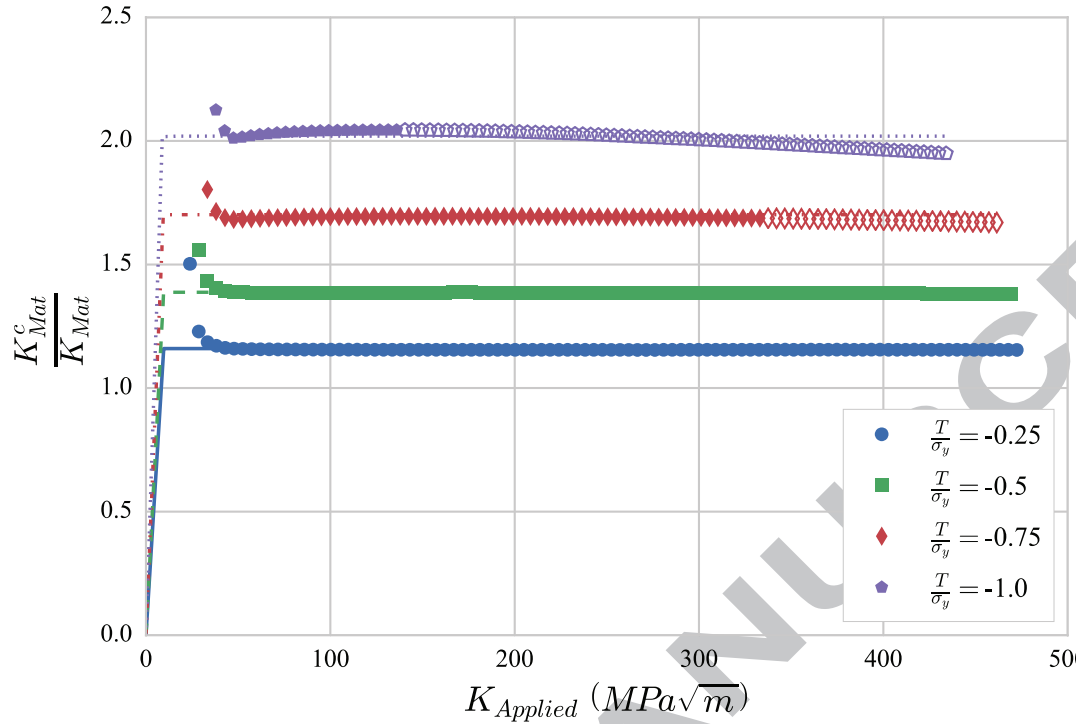

Figure 3: Plot of $K_{M a t}^{C} / K_{M a t}$ vs the applied $K, K_{\text {Applied }}$ for $n=5, E / \sigma_{y}=500$ and $\sigma_{M a x} / \sigma_{y}=$ 3.0 showing $T / \sigma_{y}=-0.25,-0.5,-0.75,-1.0$

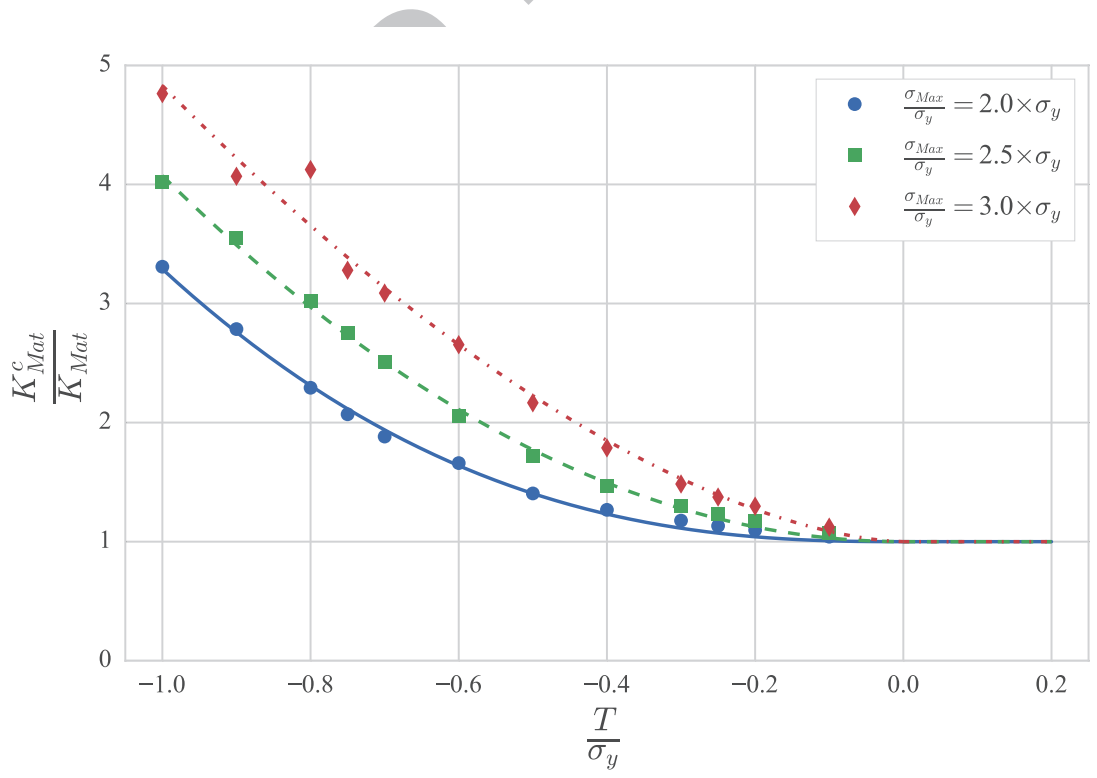

Figure 4: Plot of $K_{M a t}^{C} / K_{M a t}$ vs $T$-stress for cleavage fracture toughness, $n=10$ and $E / \sigma_{y}=$ 450 


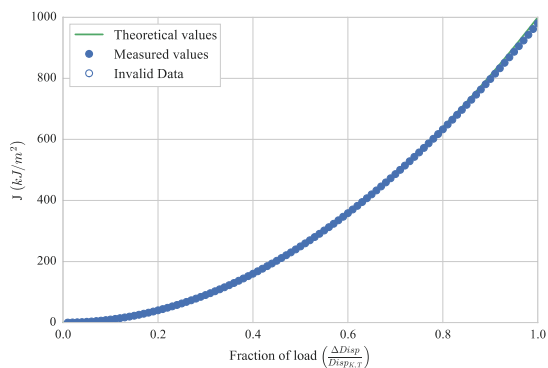

(a) $T / \sigma_{y}=0.0$

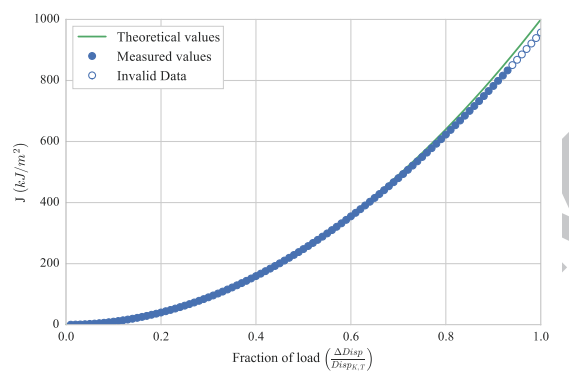

(c) $T / \sigma_{y}=-0.5$

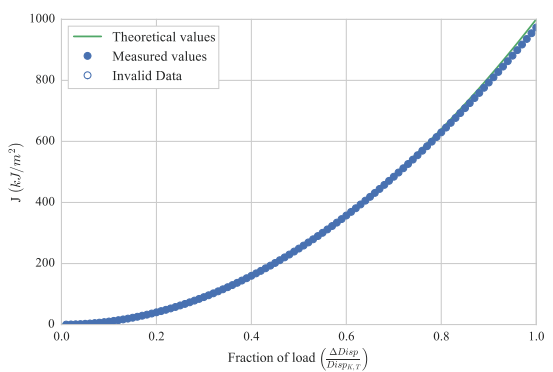

(b) $T / \sigma_{y}=-0.25$

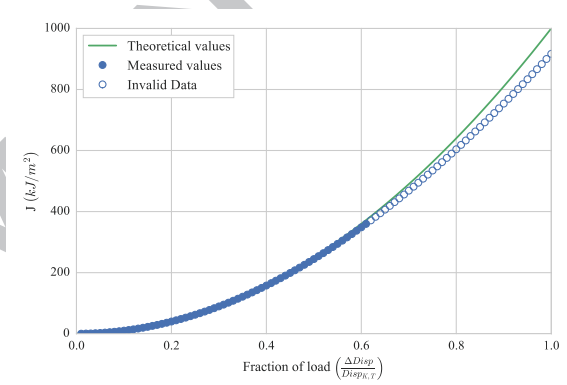

(d) $T / \sigma_{y}=-0.75$

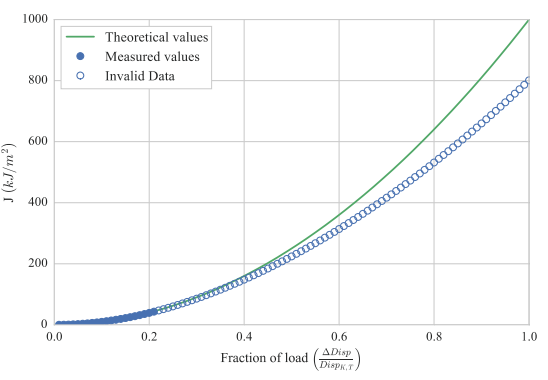

(e) $T / \sigma_{y}=-1.0$

Figure 5: Estimate of $J$ vs measured $J$ during loading for $n=7$ and $E / \sigma_{y}=550$ 


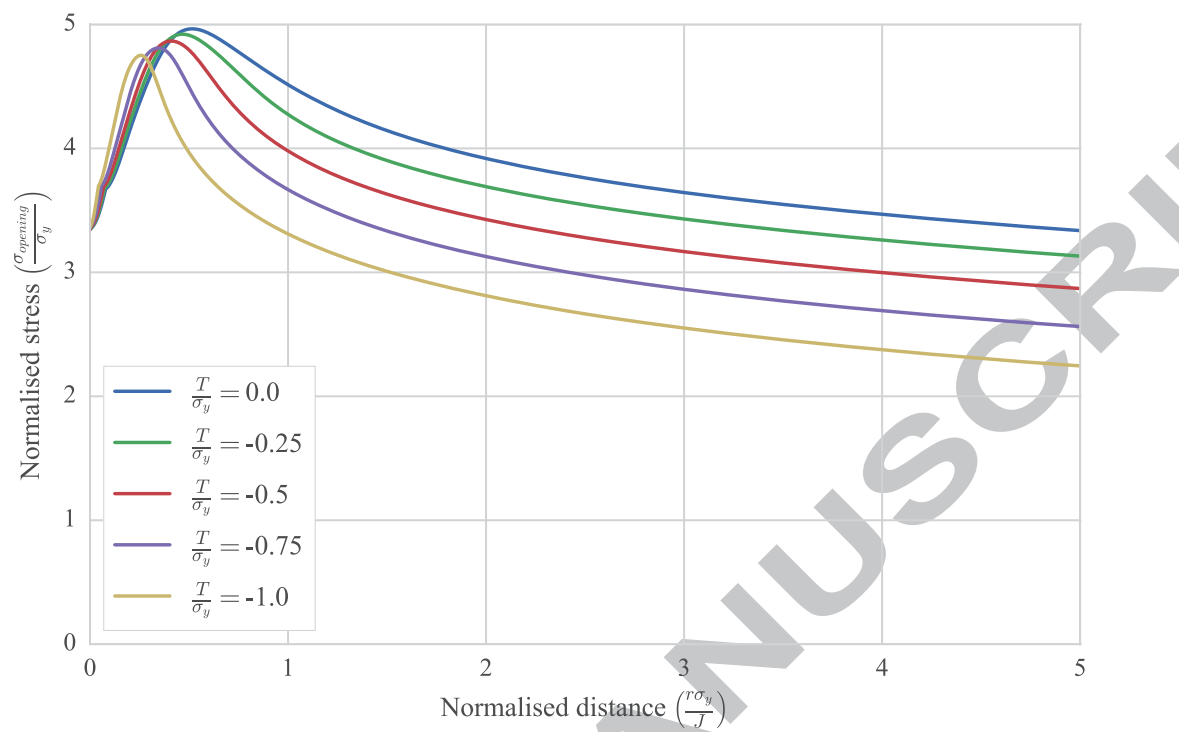

Figure 6: Normalised crack opening stress ahead of the crack tip

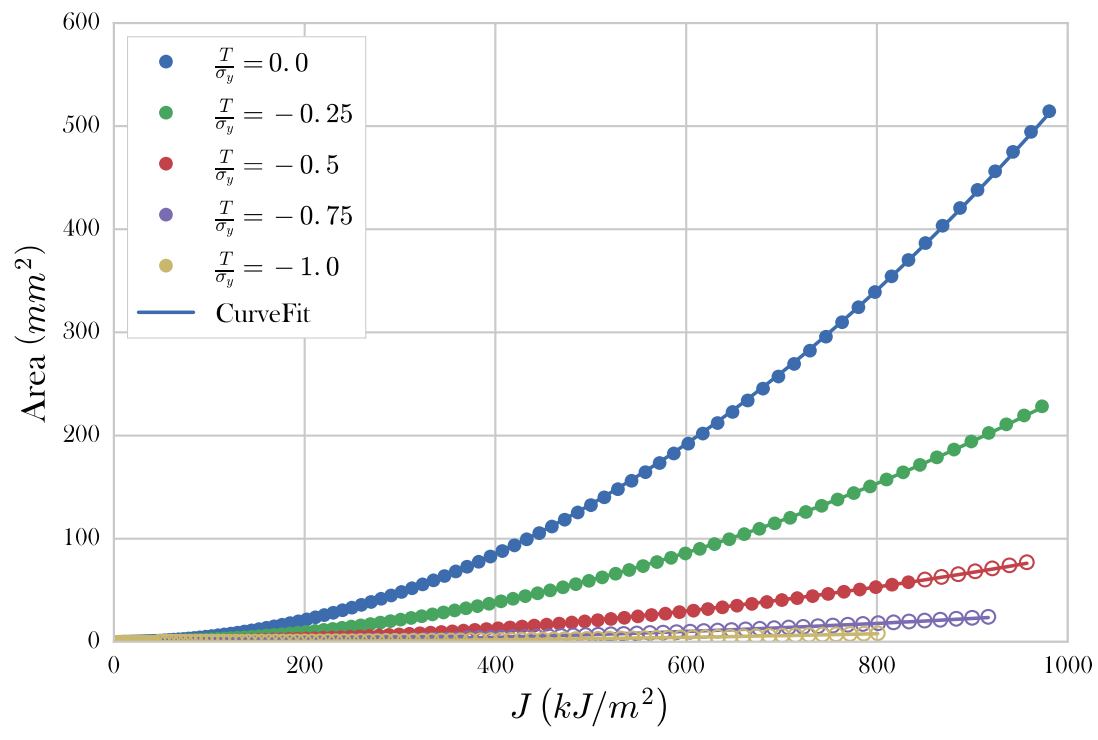

Figure 7: Typical plot of the area enclosed by the iso-stress contour equal to $3.0 \times \sigma_{y}$ as a function of $J$. Note: hollow points represent those in which the plastic zone is larger than $\frac{R}{5}$. 


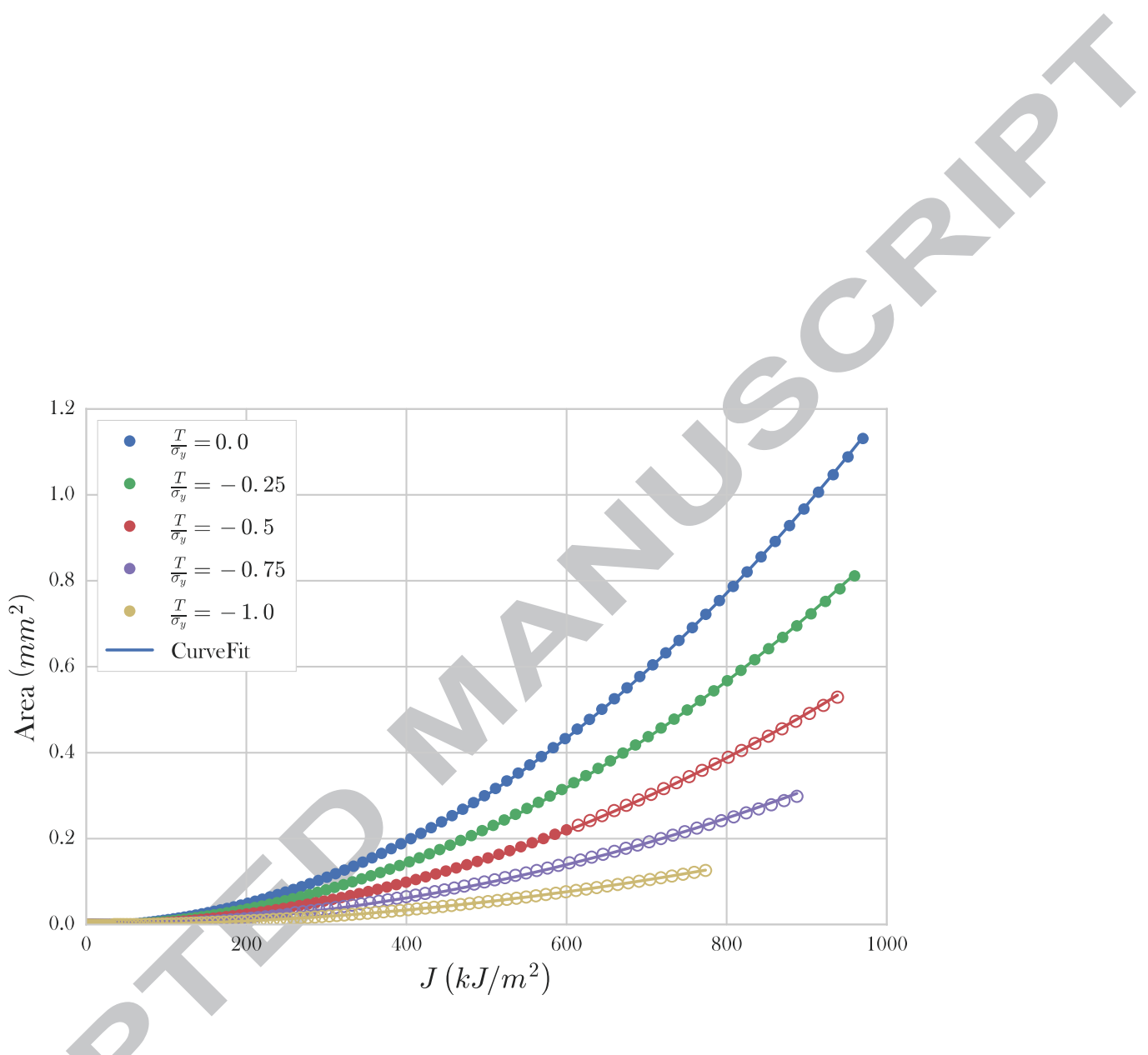

Figure 8: Typical plot of the area enclosed by the iso-Rice and Tracey contour equal to $\frac{R}{R_{0}}=2.03$ as a function of $J$. Note: hollow points represent those in which the plastic zone is larger than $\frac{R}{5}$. 


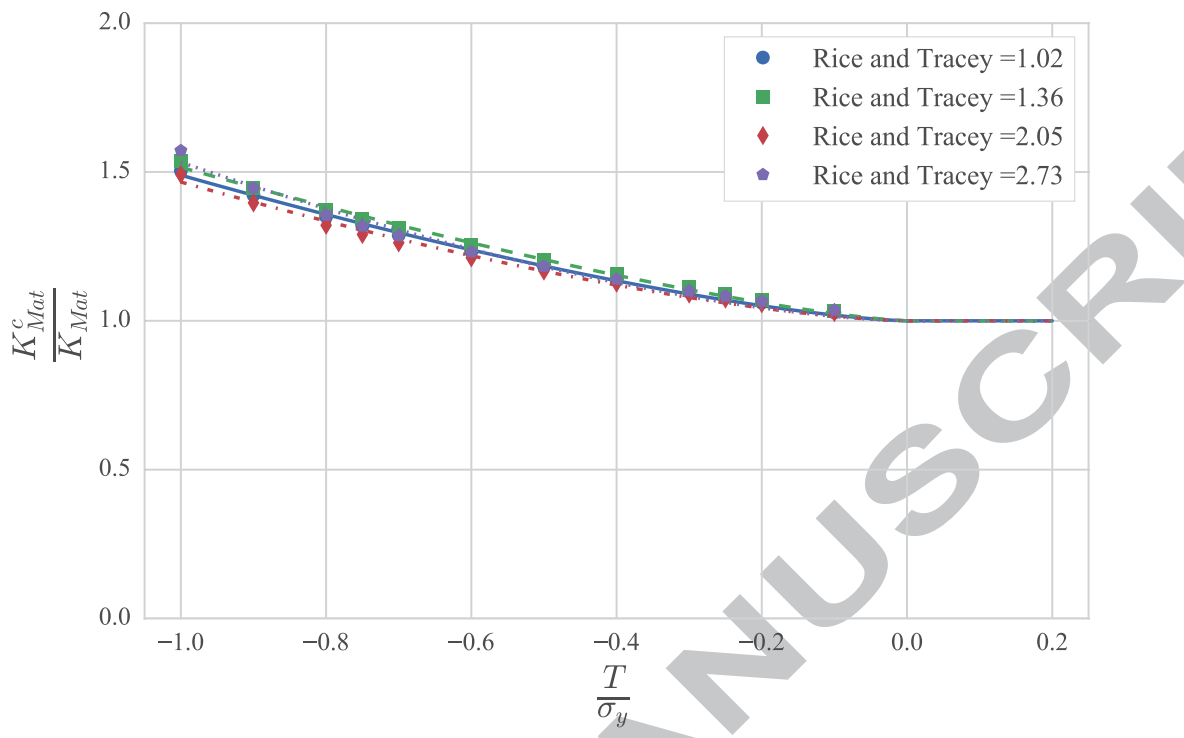

Figure 9: Plot of $K_{M a t}^{C} / K_{M a t}$ vs $T$-stress for ductile initiation fracture toughness, $n=6$ and $E / \sigma_{y}=600$

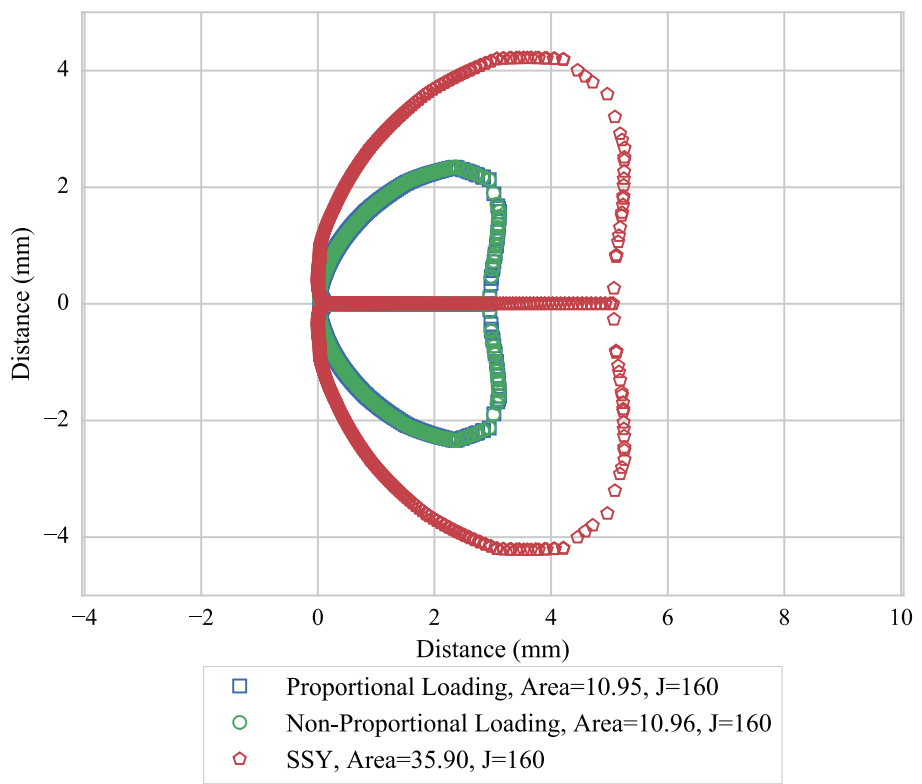

Figure 10: Comparison of the $2.5 \times \sigma_{y}$ iso-stress contours for proportionally and nonproportionally applied constraint against small scale yielding model. 


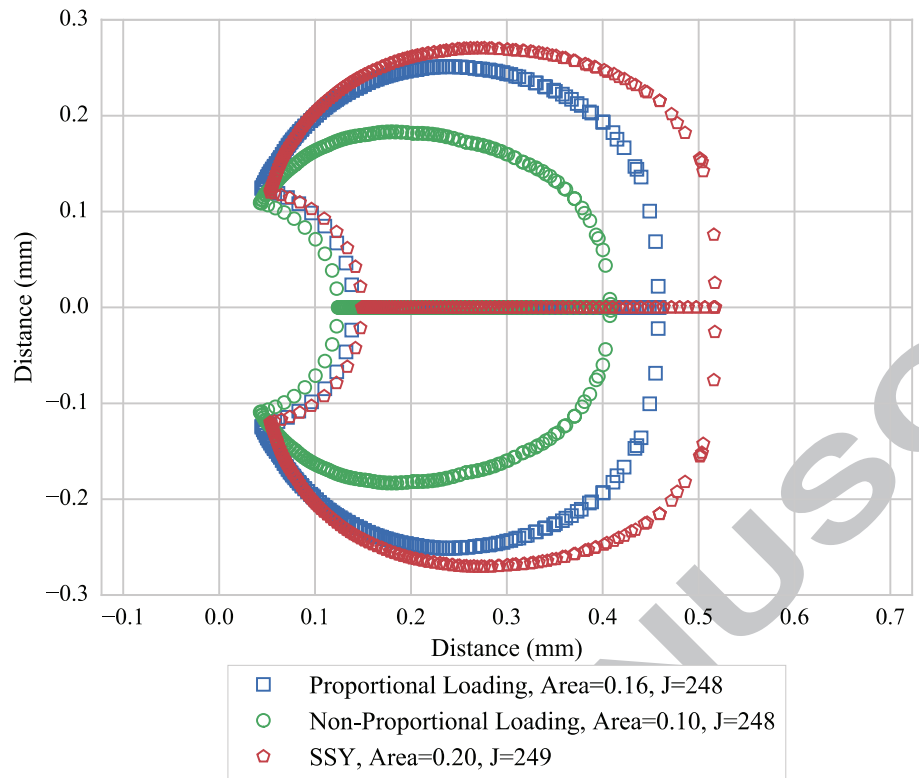

Figure 11: Comparison of the $\left(\frac{R}{R_{0}}\right)=1.36$ iso-Rice and Tracey contours for proportionally and non-proportionally applied constraint against small scale yielding model.

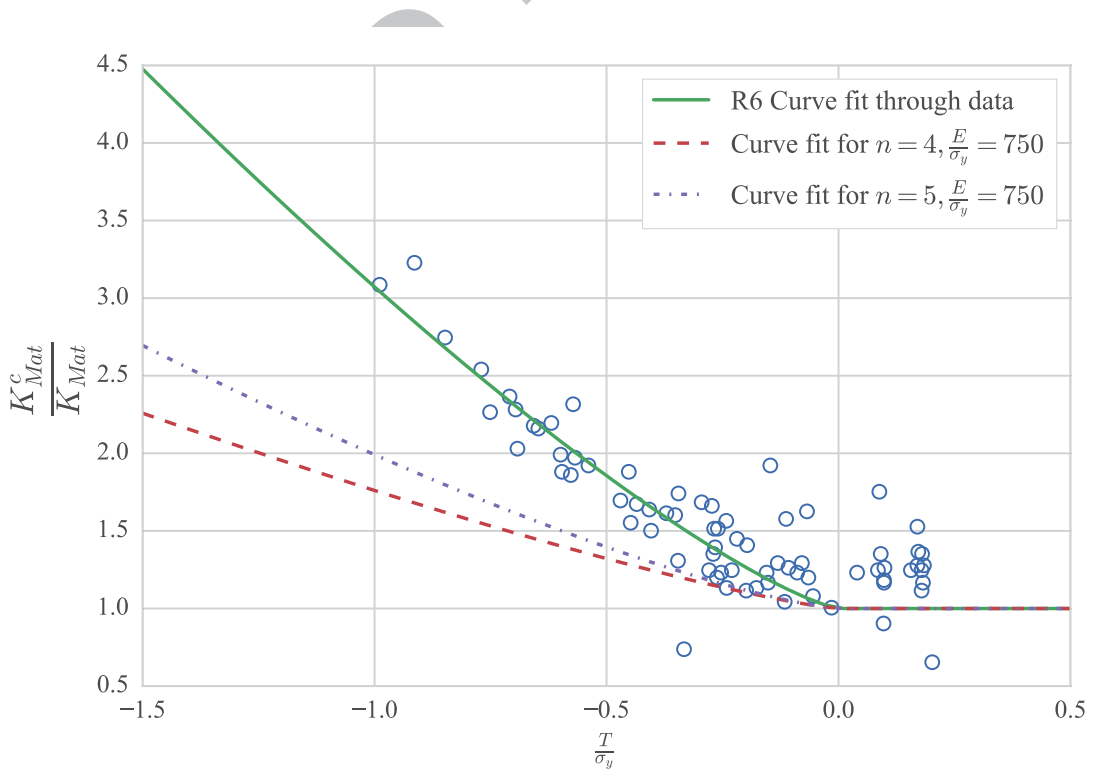

Figure 12: Comparison of benefit gained to fracture toughness from experimental data with prediction from Anderson and Dodds toughness scaling method 


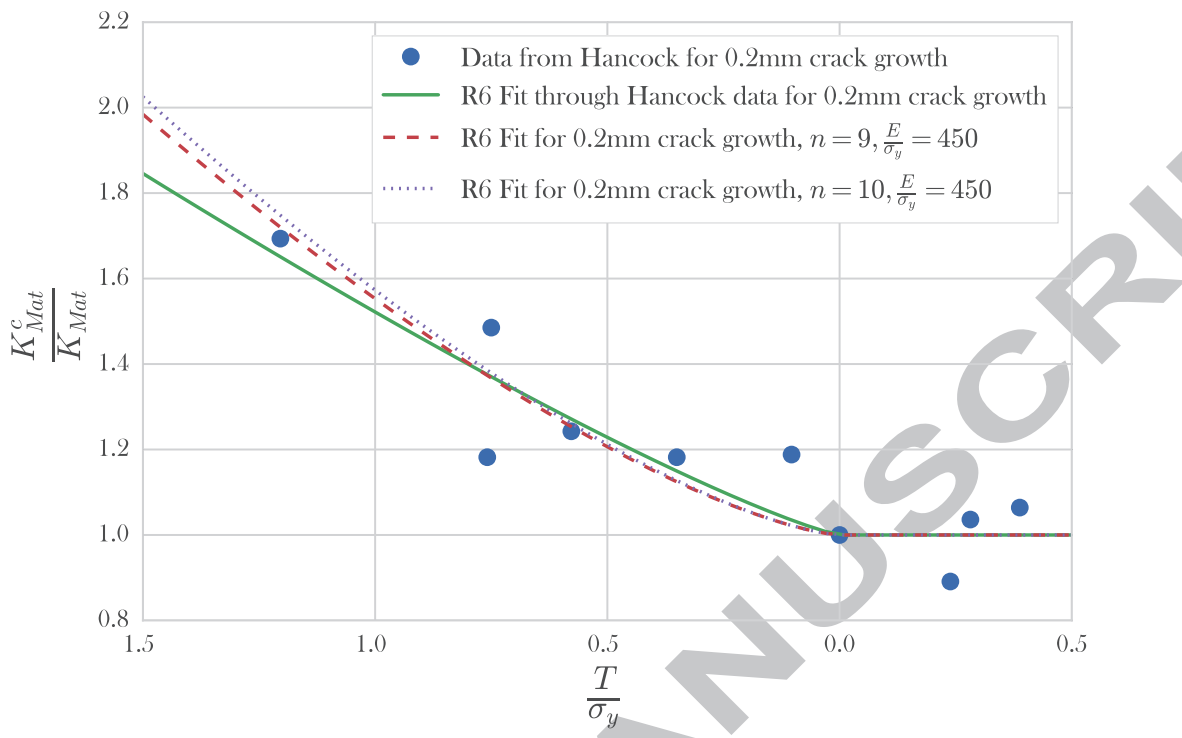

Figure 13: Comparison of benefit gained to ductile initiation fracture toughness from experimental data with prediction from Rice and Tracey contour

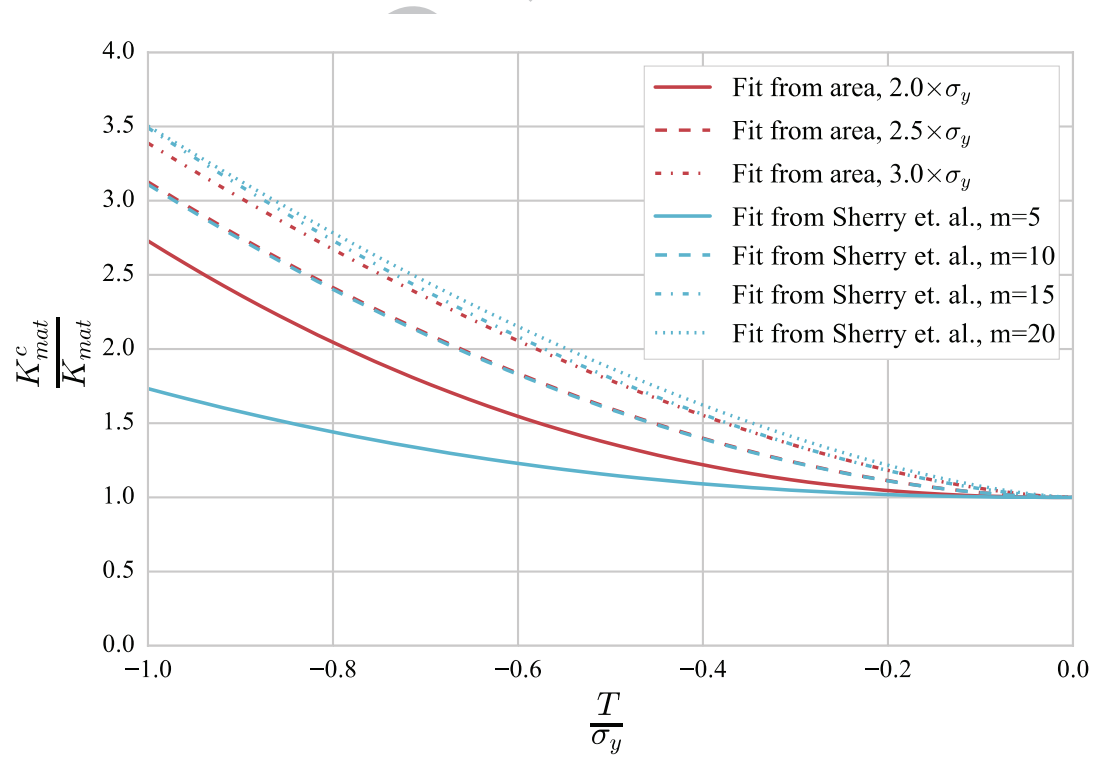

Figure 14: Comparison of benefit gained to cleavage fracture toughness from Beremin Weibull stress, and Anderson and Dodds models, $n=8$ and $E / \sigma_{y}=400$ 


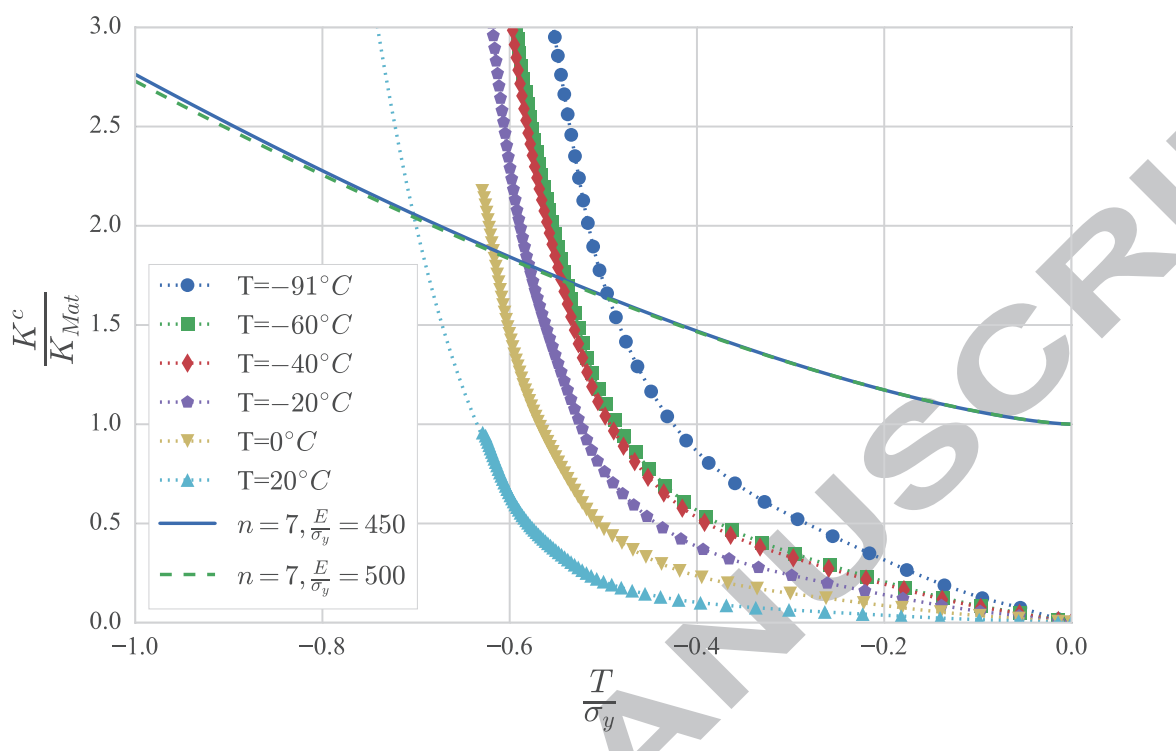

Figure 15: Predicted benefit for different temperatures and a 5\% probability of cleavage

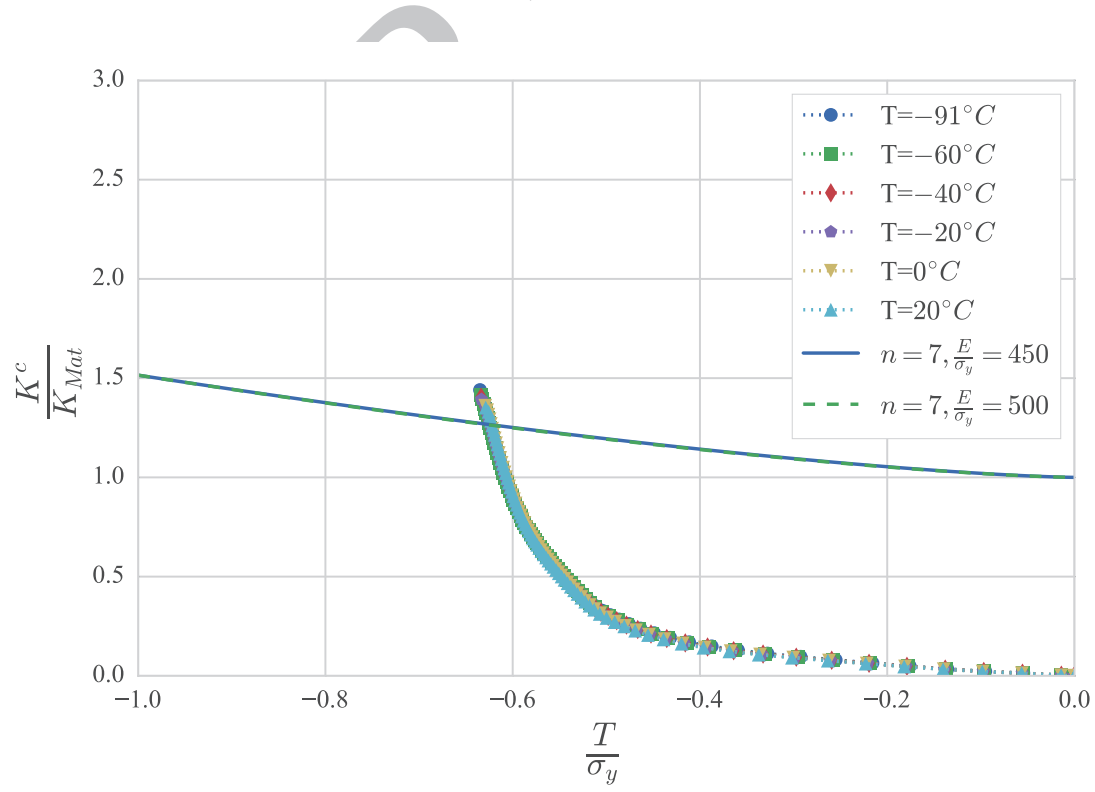

Figure 16: Predicted benefit to ductile initiation fracture toughness for different temperatures 


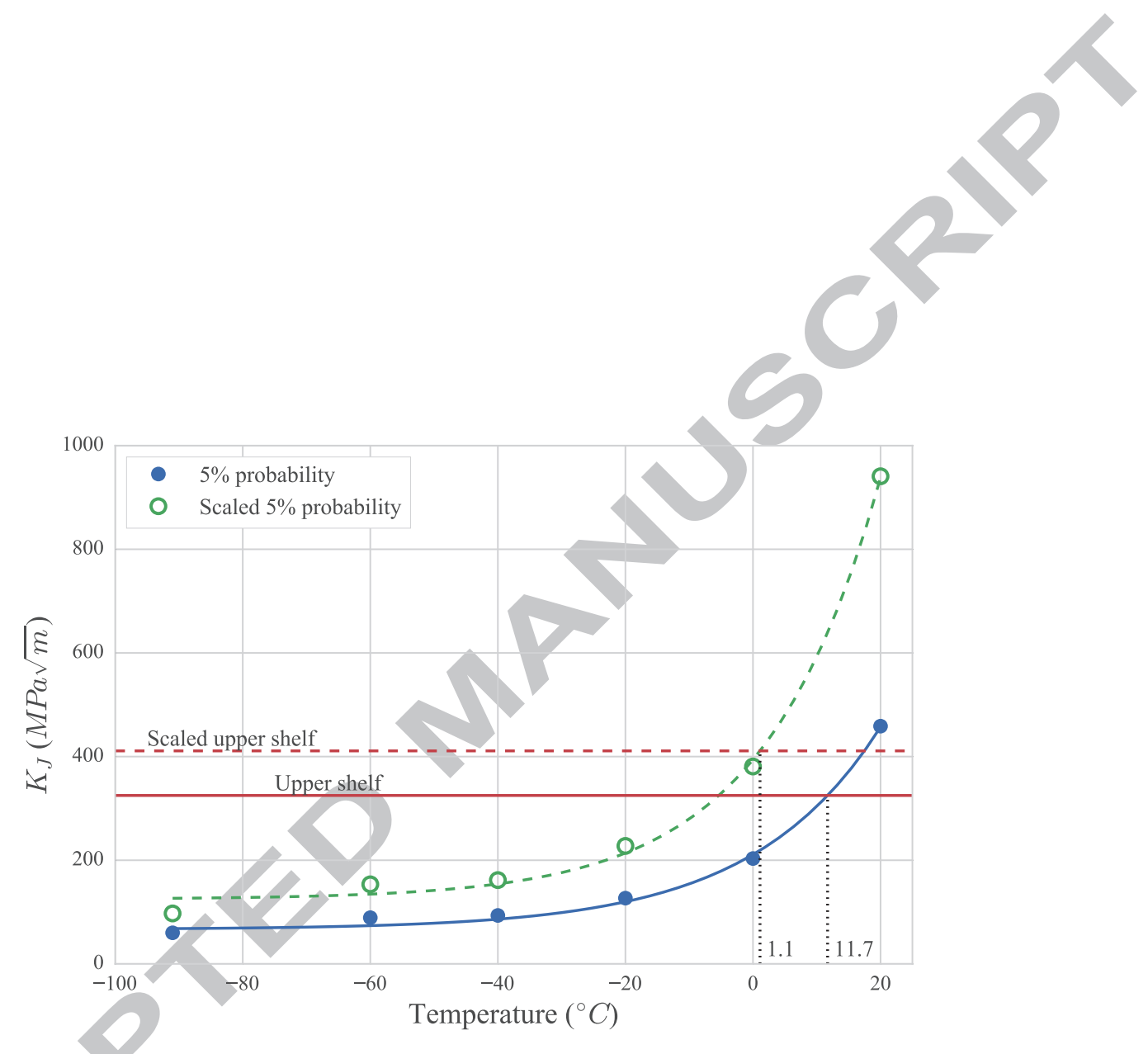

Figure 17: Modified fracture curve for a $5 \%$ probability of cleavage 
Table 1: Material property combinations tested

\begin{tabular}{llllllll}
$\frac{E}{\sigma_{y}}$ & 4 & 5 & 6 & 7 & 8 & 9 & 10 \\
\hline 350 & & & & & & $\mathrm{x}$ & $\mathrm{x}$ \\
400 & & & $\mathrm{x}$ & $\mathrm{x}$ & $\mathrm{x}$ & $\mathrm{x}$ & $\mathrm{x}$ \\
450 & $\mathrm{x}$ & $\mathrm{x}$ & $\mathrm{x}$ & $\mathrm{x}$ & $\mathrm{x}$ & $\mathrm{x}$ & $\mathrm{x}$ \\
500 & $\mathrm{x}$ & $\mathrm{x}$ & $\mathrm{x}$ & $\mathrm{x}$ & $\mathrm{x}$ & $\mathrm{x}$ & $\mathrm{x}$ \\
550 & $\mathrm{x}$ & $\mathrm{x}$ & $\mathrm{x}$ & $\mathrm{x}$ & $\mathrm{x}$ & $\mathrm{x}$ & $\mathrm{x}$ \\
600 & $\mathrm{x}$ & $\mathrm{x}$ & $\mathrm{x}$ & $\mathrm{x}$ & $\mathrm{x}$ & $\mathrm{x}$ & $\mathrm{x}$ \\
650 & $\mathrm{x}$ & $\mathrm{x}$ & $\mathrm{x}$ & $\mathrm{x}$ & $\mathrm{x}$ & $\mathrm{x}$ & $\mathrm{x}$ \\
700 & $\mathrm{x}$ & $\mathrm{x}$ & $\mathrm{x}$ & $\mathrm{x}$ & $\mathrm{x}$ & $\mathrm{x}$ & \\
750 & $\mathrm{x}$ & $\mathrm{x}$ & $\mathrm{x}$ & & & & \\
\hline
\end{tabular}

Table 2: Lookup tables for $\alpha$ and $k$ for different stress contours

\begin{tabular}{|c|c|c|c|c|c|c|}
\hline$E$ & & & \multicolumn{2}{|c|}{$2.5 \sigma_{y}$} & \multicolumn{2}{|c|}{$3.0 \sigma_{y}$} \\
\hline & & $k$ & $\alpha$ & $k$ & $\alpha$ & $k$ \\
\hline 450 & 0.794 & 1.702 & 0.802 & 1.423 & 0.742 & 1.294 \\
\hline 500 & 0.791 & 1.694 & 0.805 & 1.426 & 0.751 & 1.317 \\
\hline 550 & 0.786 & 1.681 & 0.796 & 1.422 & 0.743 & 1.18 \\
\hline 600 & 0.781 & 1.669 & 0.787 & 1.376 & 0.746 & 1.308 \\
\hline 650 & 0.775 & 1.657 & 0.785 & 1.365 & 0.73 & 1.275 \\
\hline 700 & 0.768 & 1.645 & 0.787 & 1.39 & 0.724 & 1.25 \\
\hline 750 & 0.757 & 1.589 & 0.789 & 1.415 & 0.761 & 1.242 \\
\hline
\end{tabular}

Continued on next page 
Table 2 - Continued from previous page

\begin{tabular}{ccccccc}
\hline$\frac{E}{\sigma_{y}}$ & \multicolumn{2}{c}{$2.0 \sigma_{y}$} & \multicolumn{2}{c}{$2.5 \sigma_{y}$} & \multicolumn{2}{c}{$3.0 \sigma_{y}$} \\
& $\alpha$ & $k$ & $\alpha$ & $k$ & $\alpha$ & $k$ \\
\hline$n=5$ & & & & & & \\
450 & 1.015 & 1.83 & 1.079 & 1.503 & 1.022 & 1.36 \\
500 & 1.008 & 1.859 & 1.068 & 1.512 & 1.02 & 1.346 \\
550 & 0.989 & 1.814 & 1.059 & 1.499 & 1.041 & 1.396 \\
600 & 0.981 & 1.801 & 1.051 & 1.508 & 1.013 & 1.342 \\
650 & 0.972 & 1.787 & 1.043 & 1.484 & 1.033 & 1.392 \\
700 & 0.496 & 1.363 & 0.484 & 1.349 & 0.453 & 1.48 \\
750 & 0.952 & 1.759 & 1.026 & 1.459 & 0.991 & 1.323 \\
\hline$n=6$ & & & & & & \\
400 & 1.23 & 1.972 & 1.372 & 1.613 & 1.359 & 1.396 \\
450 & 1.225 & 1.959 & 1.38 & 1.598 & 1.409 & 1.442 \\
500 & 1.218 & 1.968 & 1.368 & 1.615 & 1.432 & 1.47 \\
550 & 1.205 & 1.953 & 1.373 & 1.629 & 1.346 & 1.403 \\
600 & 1.192 & 1.934 & 1.353 & 1.621 & 1.336 & 1.397 \\
650 & 1.179 & 1.916 & 1.335 & 1.596 & 1.38 & 1.437 \\
700 & 1.166 & 1.901 & 1.321 & 1.585 & 1.329 & 1.397 \\
750 & 1.152 & 1.885 & 1.306 & 1.533 & 1.307 & 1.372 \\
\hline$n=7$ & & & & & & \\
400 & 1.471 & 2.125 & 1.734 & 1.694 & 1.773 & 1.416 \\
450 & 1.467 & 2.124 & 1.719 & 1.732 & 1.763 & 1.444 \\
500 & 1.459 & 2.08 & 1.703 & 1.707 & 1.729 & 1.431 \\
550 & 1.451 & 2.103 & 1.691 & 1.703 & 1.756 & 1.456 \\
600 & 1.443 & 2.117 & 1.682 & 1.703 & 1.707 & 1.425 \\
650 & 1.401 & 2.051 & 1.669 & 1.698 & 1.703 & 1.431 \\
700 & 1.381 & 2.029 & 1.662 & 1.703 & 1.698 & 1.433 \\
\hline \hline
\end{tabular}

Continued on next page 
Table 2 - Continued from previous page

\begin{tabular}{lcccccc}
\hline$\frac{E}{\sigma_{y}}$ & \multicolumn{2}{c}{$2.0 \sigma_{y}$} & \multicolumn{2}{c}{$2.5 \sigma_{y}$} & \multicolumn{2}{c}{$3.0 \sigma_{y}$} \\
& $\alpha$ & $k$ & $\alpha$ & $k$ & $\alpha$ & $k$ \\
\hline$n=8$ & & & & & & \\
400 & 1.729 & 2.255 & 2.126 & 1.827 & 2.388 & 1.598 \\
450 & 1.715 & 2.246 & 2.126 & 1.811 & 2.269 & 1.521 \\
500 & 1.702 & 2.228 & 2.145 & 1.786 & 2.23 & 1.519 \\
550 & 1.68 & 2.22 & 2.107 & 1.824 & 2.211 & 1.51 \\
600 & 1.663 & 2.206 & 2.066 & 1.781 & 2.115 & 1.341 \\
650 & 1.657 & 2.219 & 2.083 & 1.837 & 2.146 & 1.484 \\
700 & 1.616 & 2.168 & 2.02 & 1.78 & 2.157 & 1.444 \\
\hline$n=9$ & & & & & & \\
350 & 2.02 & 2.431 & 2.601 & 1.896 & 3.113 & 1.633 \\
400 & 2.001 & 2.393 & 2.667 & 1.997 & 3.116 & 1.682 \\
450 & 1.984 & 2.376 & 2.577 & 1.919 & 2.874 & 1.585 \\
500 & 2.0 & 2.419 & 2.559 & 1.927 & 2.799 & 1.551 \\
550 & 1.956 & 2.363 & 2.585 & 1.961 & 2.867 & 1.606 \\
600 & 1.917 & 2.338 & 2.496 & 1.874 & 2.689 & 1.488 \\
650 & 1.892 & 2.318 & 2.475 & 1.888 & 2.719 & 1.556 \\
700 & 1.887 & 2.338 & 2.441 & 1.862 & 2.662 & 1.534 \\
\hline$n=10$ & & & & & \\
350 & 2.31 & 2.55 & 3.251 & 2.048 & 4.356 & 1.833 \\
400 & 2.3 & 2.515 & 3.123 & 2.031 & 4.06 & 1.777 \\
450 & 2.289 & 2.5 & 3.074 & 1.995 & 3.83 & 1.643 \\
500 & 2.346 & 2.537 & 3.445 & 2.324 & 3.654 & 1.686 \\
550 & 2.224 & 2.487 & 2.991 & 1.968 & 3.468 & 1.587 \\
600 & 2.202 & 2.483 & 2.969 & 1.961 & 3.46 & 1.598 \\
650 & 2.159 & 2.451 & 2.964 & 1.958 & 3.313 & 1.564 \\
\hline
\end{tabular}


Table 3: Lookup tables for $\alpha$ and $k$ for initiation toughness

\begin{tabular}{|c|c|c|}
\hline$\frac{E}{\sigma_{y}}$ & $\alpha$ & $k$ \\
\hline \multicolumn{3}{|c|}{$n=4$} \\
\hline 450 & 0.476 & 1.378 \\
\hline 500 & 0.469 & 1.384 \\
\hline 550 & 0.466 & 1.382 \\
\hline 600 & 0.465 & 1.380 \\
\hline 650 & 0.465 & 1.373 \\
\hline 700 & 0.466 & 1.373 \\
\hline 750 & 0.468 & 1.371 \\
\hline \multicolumn{3}{|c|}{$n=5$} \\
\hline 450 & 0.504 & 1.408 \\
\hline 500 & 0.495 & 1.413 \\
\hline 550 & 0.492 & 1.425 \\
\hline 600 & 0.491 & 1.431 \\
\hline 650 & 0.490 & 1.433 \\
\hline 700 & 0.491 & 1.437 \\
\hline 750 & 0.492 & 1.441 \\
\hline \multicolumn{3}{|c|}{$n=6$} \\
\hline 400 & 0.503 & 1.379 \\
\hline 450 & 0.500 & 1.399 \\
\hline 500 & 0.499 & 1.413 \\
\hline 550 & 0.500 & 1.428 \\
\hline 600 & 0.500 & 1.436 \\
\hline 650 & 0.502 & 1.445 \\
\hline 700 & 0.504 & 1.453 \\
\hline 750 & 0.506 & 1.457 \\
\hline
\end{tabular}

Continued on next page 
Table 3 - Continued from previous page

\begin{tabular}{|c|c|c|}
\hline$\frac{E}{\sigma_{y}}$ & $\alpha$ & $k$ \\
\hline \multicolumn{3}{|c|}{$n=7$} \\
\hline 400 & 0.515 & 1.383 \\
\hline 450 & 0.515 & 1.404 \\
\hline 500 & 0.515 & 1.420 \\
\hline 550 & 0.517 & 1.436 \\
\hline 600 & 0.519 & 1.447 \\
\hline 650 & 0.522 & 1.458 \\
\hline 700 & 0.524 & 1.466 \\
\hline \multicolumn{3}{|c|}{$n=8$} \\
\hline 400 & 0.533 & 1.391 \\
\hline 450 & 0.533 & 1.411 \\
\hline 500 & 0.535 & 1.430 \\
\hline 550 & 0.537 & 1.446 \\
\hline 600 & 0.540 & 1.459 \\
\hline 50 & 0.543 & 1.471 \\
\hline 700 & 0.546 & 1.480 \\
\hline \multicolumn{3}{|c|}{$n=9$} \\
\hline 350 & 0.555 & 1.383 \\
\hline 400 & 0.553 & 1.402 \\
\hline 450 & 0.553 & 1.422 \\
\hline 500 & 0.555 & 1.442 \\
\hline 550 & 0.558 & 1.458 \\
\hline 600 & 0.561 & 1.473 \\
\hline 650 & 0.565 & 1.486 \\
\hline 700 & 0.568 & 1.495 \\
\hline \multicolumn{3}{|c|}{$n=10$} \\
\hline 350 & 0.575 & 1.395 \\
\hline
\end{tabular}

Continued on next page 
Table 3 - Continued from previous page

\begin{tabular}{ccc}
\hline$\frac{E}{\sigma_{y}}$ & $\alpha$ & $k$ \\
\hline 400 & 0.573 & 1.415 \\
450 & 0.573 & 1.435 \\
500 & 0.576 & 1.455 \\
550 & 0.579 & 1.473 \\
600 & 0.582 & 1.488 \\
650 & 0.586 & 1.501 \\
\hline
\end{tabular}

Table 4: Parameters for generalised solutions

\begin{tabular}{lcccc}
\hline Parameter & $2.0 \times \sigma_{y}$ & $2.5 \times \sigma_{y}$ & $3.0 \times \sigma_{y}$ & Rice \& Tracey \\
\hline Parameters for $\alpha$ & & & \\
$C_{00}$ & $1.010 \times 10^{-1}$ & 1.904 & 10.815 & $9.608 \times 10^{-1}$ \\
$C_{01}$ & $5.589 \times 10^{-4}$ & $-4.021 \times 10^{-3}$ & $-3.231 \times 10^{-2}$ & $-1.663 \times 10^{-3}$ \\
$C_{10}$ & $1.736 \times 10^{-1}$ & $-3.911 \times 10^{-1}$ & -3.560 & $-1.223 \times 10^{-1}$ \\
$C_{11}$ & $-2.886 \times 10^{-4}$ & $8.938 \times 10^{-4}$ & $1.082 \times 10^{-2}$ & $4.081 \times 10^{-4}$ \\
$C_{02}$ & $-8.034 \times 10^{-7}$ & $2.154 \times 10^{-6}$ & $2.505 \times 10^{-5}$ & $1.238 \times 10^{-6}$ \\
$C_{20}$ & $2.560 \times 10^{-3}$ & $4.873 \times 10^{-2}$ & $3.206 \times 10^{-1}$ & $8.750 \times 10^{-3}$ \\
$C_{12}$ & $3.516 \times 10^{-7}$ & $-3.050 \times 10^{-7}$ & $-8.342 \times 10^{-6}$ & $-3.043 \times 10^{-7}$ \\
$C_{21}$ & $3.545 \times 10^{-5}$ & $-3.003 \times 10^{-5}$ & $-8.727 \times 10^{-4}$ & $-2.603 \times 10^{-5}$ \\
$C_{22}$ & $-4.412 \times 10^{-8}$ & $-1.856 \times 10^{-8}$ & $6.645 \times 10^{-7}$ & $2.023 \times 10^{-8}$ \\
Parameters for $k$ & & & \\
$D_{00}$ & $3.222 \times 10^{-1}$ & 2.518 & 2.554 & 1.621 \\
$D_{01}$ & $3.065 \times 10^{-3}$ & $-4.069 \times 10^{-3}$ & $-4.335 \times 10^{-3}$ & $-2.501 \times 10^{-4}$ \\
$D_{10}$ & $3.240 \times 10^{-1}$ & $-2.774 \times 10^{-1}$ & $-5.462 \times 10^{-1}$ & $-1.008 \times 10^{-1}$ \\
$D_{11}$ & $-6.460 \times 10^{-4}$ & $9.131 \times 10^{-4}$ & $1.834 \times 10^{-3}$ & $1.601 \times 10^{-4}$ \\
\hline
\end{tabular}

Continued on next page 
Table 4 - Continued from previous page

\begin{tabular}{lcccc}
\hline Parameter & $2.0 \times \sigma_{y}$ & $2.5 \times \sigma_{y}$ & $3.0 \times \sigma_{y}$ & Rice \& Tracey \\
\hline$D_{02}$ & $-2.850 \times 10^{-6}$ & $2.471 \times 10^{-6}$ & $2.976 \times 10^{-6}$ & $-6.058 \times 10^{-7}$ \\
$D_{20}$ & $-9.518 \times 10^{-3}$ & $1.723 \times 10^{-2}$ & $5.574 \times 10^{-2}$ & $5.312 \times 10^{-3}$ \\
$D_{12}$ & $5.503 \times 10^{-7}$ & $-4.520 \times 10^{-7}$ & $-1.336 \times 10^{-6}$ & $1.287 \times 10^{-7}$ \\
$D_{21}$ & $3.256 \times 10^{-5}$ & $-2.382 \times 10^{-5}$ & $-1.721 \times 10^{-4}$ & $-4.357 \times 10^{-6}$ \\
$D_{22}$ & $-2.783 \times 10^{-8}$ & $-8.874 \times 10^{-9}$ & $1.269 \times 10^{-7}$ & $-1.274 \times 10^{-8}$ \\
\hline
\end{tabular}

Table 5: Data extracted from Hancock et. al. $<19>$

\begin{tabular}{cccc}
$T / \sigma_{y}$ & $J k J / m^{2}$ & $J / J^{t=0}$ & $K_{I} / K_{I}^{T=0}$ \\
\hline 0.39 & 355 & 1.132 & 1.064 \\
0.28 & 336 & 1.074 & 1.036 \\
0.24 & 249 & 0.794 \\
$0.00^{*}$ & 313 & 1.000 & 0.891 \\
-0.10 & 442 & 1.412 & 1.000 \\
-0.35 & 438 & 1.397 & 1.188 \\
-0.58 & 484 & 1.544 & 1.182 \\
-0.75 & 691 & 2.206 & 1.243 \\
-0.76 & 438 & 1.397 & 1.485 \\
-1.20 & 899 & 2.868 & 1.182 \\
\hline
\end{tabular}

Measured from a least squares regression of tests with a positive $T$-stress 
Table 6: Estimates of lower bound ( $5 \%$ probability of cleavage) fracture toughness for 'Euro' data set

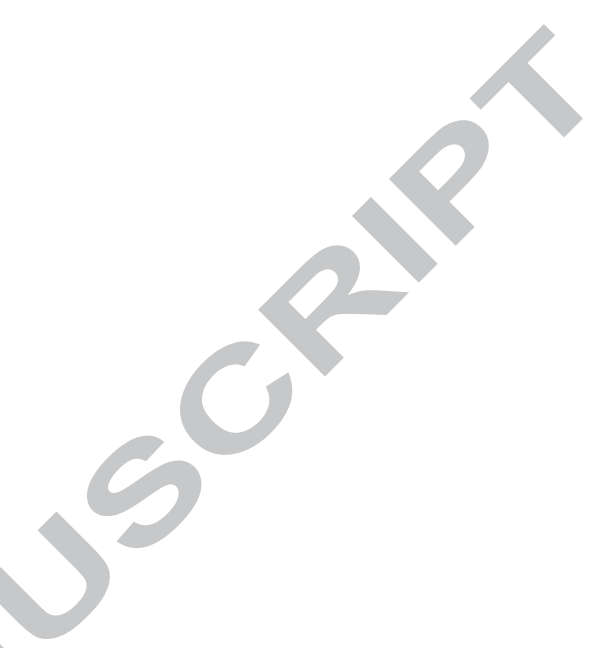

\begin{tabular}{cc} 
& \\
Temperature $\left({ }^{\circ} \mathrm{C}\right)$ & $K_{J}(M P a \sqrt{m})$ \\
\hline-91 & 60.0 \\
-60 & 89.2 \\
-40 & 93.5 \\
-20 & 126.9 \\
0 & 203.3 \\
20 & 458.7 \\
\hline
\end{tabular}

